\title{
Extractions in Tsou causative applicatives
}

\author{
Henry Y Chang
}

\author{
Correspondence: \\ henryylc@sinica.edu.tw \\ Institute of Linguistics, Academia \\ Sinica, Taipei, Taiwan
}

\begin{abstract}
This paper investigates the extraction of an internal argument as the trigger in Tsou applicatives. It is observed that a locative applicative (LA) advances as the trigger an indirect object $(\mathrm{IO})$, not a direct object $(\mathrm{DO})$, whereas a(n) instrumental/benefactive applicative seems to advance either an IO or a DO. In this paper, I argue that the seemingly DO extraction in an IA is actually an $I O$ extraction and that the DO is anteceded by an $1 \mathrm{O}$ introduced by an IA head that functions as the matrix predicate of a complex predicate. The complex predicate analysis is supported by the fact that an IA with the seemingly DO extraction is required to take a ditransitive verb as its complement and receives a double transitive marking. The complex predicate analysis also applies to a double applicative, where an IA is stacked over an LA. A double transitive is believed to instantiate the well-motivated conceptualization of a transported theme/causand as an instrument and a double applicative that of a goal as a beneficiary.

Keywords: Extraction; Instrumental/benefactive applicative; Locative applicative; Ditransitive; Causative; Double transitive; Double applicative; Tsou
\end{abstract}

\section{Background}

This paper deals with extractions in Tsou causative applicative constructions (CA hereafter) in light of the Minimalist Program (Chomsky 2000, 2001, 2008). While there is a considerable amount of literature on Austronesian "focus/voice," very little attention is paid to the investigation of Austronesian CAs, let alone the inquiry of them from a Minimalist perspective. This paper aims to fill the gap.

Before entering into the detailed discussion of Tsou CAs, a few clarifications on the terminology and the range of this paper are in order. This paper is focused on threeargument applicatives, which include both three-argument CAs and "ditransitive" applicatives. While the term "ditransitive" is used throughout the paper, it should be noted that the term does not mean the same thing as what has been understood in the literature. In this paper, the term is intended for a three-argument (triadic) verb that is typically marked by applicative morphology in Tsou; it does not refer to a double object construction (DOC). As observed by H. Chang (2011b), there is no DOC in Tsou since one of the three arguments must be in the oblique case.

Most of the previous studies on applicatives are concerned with accusative languages, notably Germanic languages like English and Bantu languages like Chichewa and Kichaga. It is less known how applicativization works in ergative

(c) 2015 Chang; licensee Springer. This is an Open Access article distributed under the terms of the Creative Commons Attribution License (http://creativecommons.org/licenses/by/4.0), which permits unrestricted use, distribution, and reproduction in any medium, provided the original work is properly credited. 
languages. As an ergative language (Chang 2011a), Tsou can illustrate how ergative applicatives are syntactically derived and how they differ from their accusative counterparts, thereby shedding new lights on the theory of applicatives.

Two types of extraction asymmetries are distinguished in Tsou CAs, with instrumental CAs displaying a seemingly reverse extraction pattern from their locative counterparts. As will become clear shortly, what looks like a two-way distinction in DP extractions turns out to be a uniform extraction pattern.

In the context of Chomsky's phase theory, the present paper endorses one of the two competing phase-based accounts in the Austronesian literature-I adopt Aldridge's (2004, 2005, 2008a, b) view rather than Rackowski and Richards's perspective and treat what have been labeled as focus/voice markers in the literature as light verbs/applicative heads instead of as markers of Case agreement, as will be reviewed in sections The Case agreement approach-The ergative/light-verb analysis.

The paper is organized as follows. Section The target language and theoretical framework briefly introduces the basic grammar of Tsou and the theoretical framework adopted in the paper. More precisely, the brief introduction consists of both a grammatical sketch of Tsou and a quick summary of Chomsky's phase theory. Section Extraction asymmetries presents the seemingly CA extraction asymmetries in Tsou and how they are accounted for in the Austronesian literature. Section Phase theory of applicatives proposes a complex predicate analysis of CAs and argues that the trigger extractions consistently start from SpecApplP in Tsou. Section Concluding remarks concludes the paper with some discussions on its typological and theoretical implications.

\section{The target language and theoretical framework}

\section{A grammatical sketch of Tsou}

Tsou is an Austronesian language spoken in the south-western highlands of Taiwan. As argued in Chang (2011a), Tsou is an ergative language. In a typological perspective (Dixon 1994), this means that in Tsou, a transitive object O patterns grammatically on a par with an intransitive subject $S$, as opposed to a transitive subject A. In a Minimalist perspective (Aldridge 2004, 2005, 2008a), this means that a direct object is valued with the same structural case, namely, the absolutive case, as an intransitive external argument.

In Tsou, a predicate typically precedes its arguments and the adjuncts associated with it, with one of the arguments profiled as the most prominent DP and occurring sentence-finally. Following Pearson (2005), I label the most prominent argument of a Tsou sentence as the trigger. A trigger is morphologically indexed on the verb, led by an absolutive case marker. As in other western Austronesian languages, Tsou exhibits the absolutive restriction on relativization-only the absolutively marked trigger can be relativized (M. Chang 2004). It is also understood that the trigger shifts to the top position of the sentence. As in 1, the reflexive trigger iachisi 'himself' occurs external to a temporal adverbial ne hucma 'yesterday'. Given that temporal adverbials of this sort have been proven to merge in the domain of TP cross-linguistically (Cinque 1999), the reflexive trigger in question should have moved from its base position within VP to a position around or above $\mathrm{TP}^{\mathrm{a}}$. 
(1) i-si_koic-a_to_mo'o_ne hucma_'o_iachi-si.

TR.RL-3SG.ERG_scold-TR_ERG_PN_yesterday_ABS_self-3SG.POSS ${ }^{\mathrm{b}}$

He scolded himself yesterday.

In addition to absolutive case markers, Tsou also has ergative case markers that encode a transitive external argument, and oblique case markers that mark syntactic arguments other than the absolutive and the ergative ${ }^{c}$. Every sentence almost always starts with a mood auxiliary that indicates the temporal status of the sentence, with an additional encoding of grammatical transitivity in its realis mood, as summarized in Table 1 below.

What is most relevant to the main point of this paper is that a lexical verb is morphologically marked for grammatical transitivity. There is a grammatical transitivity concord between a lexical verb and the mood auxiliary. As in $2 \mathrm{a}$, the intransitive lexical verb mosi co-occurs with an intransitive mood auxiliary mo; in contrast, the transitive lexical verbs sia, sii, and sieni pattern with a transitive mood auxiliary $i$-, as in $2 \mathrm{~b}$-d.

(2) a. mo__mo-si_ta_pangka_to_emi__o_amo.

INTR.RL_INTR-put_OBL_table_OBL_wine_ABS_father

Father put wine on the table.

b. i-si_si-a_to_amo_ta_pangka_o_o_emi.

TR.RL-3SG.ERG_put-TR_ERG_father_OBL_table_ABS_wine

Father put the wine on the table.

c. i-si_si-i_ta_amo_ta_emi_'o_pangka.

TR.RL-3SG.ERG_put-LA_ERG_father_OBL_wine_ABS_table

Father put the wine on the table.

d. i-si_si-eni_ta_amo_ta_emi_(na)_a'o.

TR.RL-3SG.ERG_put-IA_ERG_father_OBL_wine_ABS_1SG.ABS

Father put the wine for me.

As exemplified in 2a-d, the basic word order of constituents in a sentence is AUX > VERB > ERG > OBL > ABS, where the sign '>' means 'precede'.

Importantly, grammatical transitivity should be distinguished from semantic transitivity. A gramatically intransitive sentence takes only one core argument, though its verb may semantically select more than one argument. The example in 2a above is a case in point. There is only one core argument, i.e., the absolutive amo 'father', in the sentence, though its main verb is a three-place predicate mosi 'put'. In contrast, the examples in $2 \mathrm{~b}-2 \mathrm{~d}$ are transitive, since there are two core arguments, namely, the ergative and the abolutive, in the sentences. Note, in particular, that transitive sentences are further divided into two subcategories: plain transitives versus applicatives. In a plain transitive sentence such as $2 b$, the main verb is marked by the suffix $-a$ (glossed as TR) and its

Table 1 The mood auxiliary in Tsou ${ }^{\mathrm{d}}$

\begin{tabular}{llllll}
\hline $\begin{array}{lllll}\text { Reality } \\
\text { Proximity }\end{array}$ & Realis & & & Irrealis \\
\cline { 2 - 3 } \cline { 5 - 6 } & INTR & TR & & General & Counterfactual \\
\hline Proximate & mi-, mo & $\mathrm{i}-$, os- & te, ta- & nte \\
Remote & moh, moso & oh- & tena & nto, ntoh- \\
\hline
\end{tabular}


patient argument occurs typically as the absolutive trigger. Applicatives are of two types, namely, locative and instrumental applicative. A locative applicative (LA) is so-called because it normally chooses a locative argument, including a location, a source, and a goal, as its absolutive trigger, with its main verb marked by the suffix $-i$, as already exemplified in 2c. An instrumental applicative (IA) is a cover term for an instrumental applicative and a benefactive applicative; its main verb is marked with the suffix -(n)eni. Canonically, an IA takes as its absolutive trigger either a beneficiary, as shown in $2 \mathrm{~d}$ above, or an instrument, as illustrated in 3a-b below.

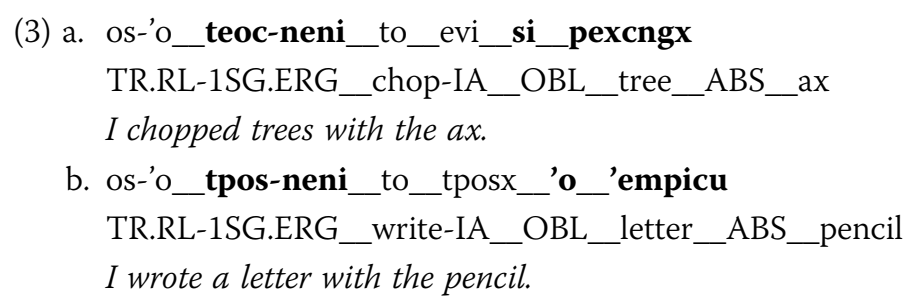

Table 2 summarizes the markings of grammatical transitivity in Tsou.

I shall address the extensions of locative and instrumental applicatives in section Causatives.

\section{Dispensing with the high-low applicative distinction}

Since Pylkkänen $(2002,2008)$, applicatives are usually divided into two classes in terms of their semantic property and syntactic position/behavior. A high applicative (ApplH) introduces an individual to an event described by the verb; it is merged above VP and able to pattern with intransitive and stative verbs. A low applicative (ApplL), in contrast, brings an entity to the possession of another individual; it is situated down inside the VP and thus co-occurs only with transitive and dynamic verbs. Table 3 sums up how the high-low applicative distinction is made in Pylkkänen's analysis.

Along this line of thought, Chang (2004) analyzes Tsou applicatives headed by -(n)eni as high applicatives and those headed by $-i$ as low applicatives.

However, this widely held high-low applicative analysis faces robust challenges recently. Larson (2010) dismisses Pylkkänen's semantic computation of low applicatives and argues that Pylkkänen's analysis gives rise to undesirable inferences. He suggests that we should go back to the standard Neo-Davidsonian framework and treat the socalled low applicatives as involving a relation of an individual to an event. This amounts to saying that the high-low applicative distinction is non-existent and that all applicatives are high applicatives. In a similar vein, Paul and Whitman (2010) and Georgala (2012) reject Pylkkänen's thesis on the basis of semantic and grammatical

Table 2 Markers of grammatical transitivity in Tsou

\begin{tabular}{lll}
\hline & Mood auxiliary & Lexical verb \\
\hline Grammatically intransitive & $m i-, m o$, moh-, moso & $<m>/ \varnothing$ \\
Grammatically transitive & $i$, os-, oh- & $-a$ (plain transitive, TR) \\
& & $-i$ (locative applicative, LA) \\
& $-(n)$ eni (instrumental applicative, IA) \\
\hline
\end{tabular}


Table 3 Collocation tests for the high-low applicative dichotomy

\begin{tabular}{lll}
\hline Test & ApplH & ApplL \\
\hline Does it pattern with an intransitive verb? (semantic transitivity test) & Yes & No \\
Does it pattern with a stative verb? (dynamicity test) & Yes & No \\
\hline
\end{tabular}

evidence and put forward an alternative proposal that places all applicatives consistently above VP. Meanwhile, H. Chang (2010) revisits M. Chang's high-low applicative distinction and observes that what has been taken as low applicatives (i.e., $i$-applicatives) turns out to behave like high applicatives in Tsou. In this paper, I argue alongside with Larson/ Paul and Whitman/Georgala/H. Chang that Tsou applicatives are all high applicatives.

There is no question of identifying IAs as high applicatives in Tsou. We have demonstrated in 1-2 that an IA relates either a beneficiary or an instrument to an event. This aligns an IA with a high applicative. An additional support of the analysis comes from the fact that an IA can apply to stative and intransitive verbs, as in 4 .

(4) os-'o_kaeb-eni_si_paicx

TR.RL-1SG.ERG_happy-IA_ABS_PN

I am happy for Paicx.

On the other hand, the structural status of an LA is not that straightforward. At first glance, an LA looks like a low applicative, given that (i) it may involve a transfer of possession, as in 5; (ii) it does not appear to apply to unergative verbs, as in 6.

(5) a. os-'o_pai'un-i_to_tposx_'o__mo'o

TR.RL-1SG.ERG_send-LA_OBL_book_ABS_PN

I sent Mo'o a book.

b. i-si_fi-i_ta_peisu_ta_mo'o_si_paicx.

TR.RL-3SG.ERG_give-LA_OBL_money_ERG_PN_ABS_PN

Mo'o gave money to Paicx.

(6) a. *i-si_ngsi-i_'o_teova

TR.RL-3SG.ERG_cry-LA_ABS_hut

Intended for He cried at the hut.

b. *i-si_coecon-i__o_coca

TR.RL-3SG.ERG_walk-LA_ABS_yard

Intended for He walked in the yard.

However, a closer inspection shows that this is not the case ${ }^{\mathrm{e}}$. First, an LA can apply to posture verbs, which are semantically neither transitive nor dynamic, as in 7.

(7) a. i-ta_yac'-i_si_fatu ${ }^{6}$

TR.RL-3SG.ERG_stand-LA_ABS_stone

He stands on the stone.

b. i-si_yusuhng-i_'o__hopo

TR.RL-3SG.ERG_sit-LA_ABS_bed

He sits on the bed. 
Second, an LA can productively pattern with verbs of perception and cognition, which are by no means dynamic. For instance:

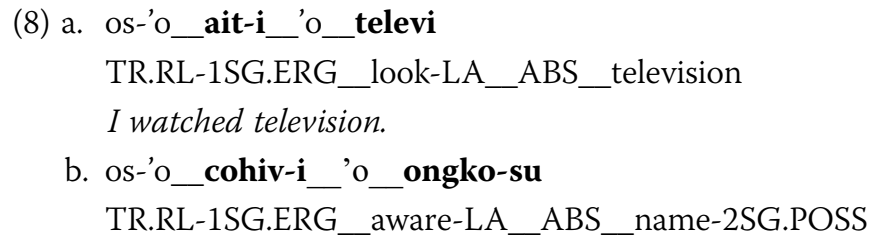

Even if we apply Pylkkänen's dynamicity and semantic transitivity tests, we shall reach the conclusion that an LA should occur as a high applicative instead of a low applicative in Tsou.

\section{EPP/EF-driven movement}

In the Minimalist program, syntactic operations Move and Agree, which involve a Probe-Goal relation, are motivated by the deletion of an uninterpretable feature on the Probe. In this conception, an A'-movement such as wh-movement is triggered by an uninterpretable edge feature $(\mathrm{EF})$ rather than by an interrogative $\mathrm{Q}$ feature on $\mathrm{C}$; an A-movement such as raising is induced by an uninterpretable EPP feature on the Probe $T$ instead of an uninterpretable structural Case feature on the Goal. Chomsky dubs this enlightened self-interest principle as the Suicidal Greed.

(9) The Suicidal Greed (Chomsky 2000: 127)

The movement of a Goal is driven by the uninterpretable feature on its matching Probe.

This revised view can better explain why a wh-phrase remains in situ in Mandarin Chinese while its English counterpart must be displaced and why a nominatively casemarked DP can remain in the object position while an obliquely case-marked DP shifts to the subject position in Icelandic (Sigurðsson 2004). It also gives a nicer account for why in an ergative language, a transitive object must shift out of VP though it can receive Case in its base position from a local transitive $v$, as already illustrated in 1 .

\section{Phase theory}

In the Minimalist Program, Chomsky develops a theory of syntactic derivations (Chomsky 2000, 2001, 2008). In the phase theory, syntactic derivations proceed by phase-derivations take place successively and cyclically from a lower phase to the next higher phase(s). Each phase is a self-contained subsection, with independent phonological and semantic attributes. A phase is thus characteristic of the following properties:

(10) Phase properties (Based on Chomsky 2000, 2001, 2008)

a. A phase head is functional (rather than lexical);

b. A phase is either propositional or eventive;

c. An eventive phase should introduce an external argument; 
d. A transitive phase head may bear a structural case feature;

e. A phase head may bear an edge feature (EF);

f. A phase is phonologically independent.

In terms of these criteria, Chomsky identifies CPs and transitive $\nu$ Ps as phases, excluding TPs, intransitive $v \mathrm{P}$ and VPs. While transitive $v$ Ps are identified as phases, their intransitive counterparts are not, owing to their lack of an external argument and a structural case ${ }^{\mathrm{g}}$.

Derivations by phase are constrained by locality conditions. A phase head can only probe a closest goal within its c-commanding domain. This is known as Attract Closest Principle (ACP) or the Minimal Link Condition (MLC):

(11) The ACP (Chomsky 1995: 297)

A head which attracts a given kind of constituent attracts the closest constituent of the relevant kind.

(12) The MLC (Chomsky 1995: 311)

$\mathrm{K}$ attracts $\alpha$ only if there is no $\beta, \beta$ closer to $\mathrm{K}$ than $\alpha$, such that $\mathrm{K}$ attracts $\beta$.

The MLC/ACP can account for the following phenomena in a principled manner. In 13a, the sentence is likely to be ruled out by what a pre-Minimalist approach identifies as the Head Movement Constraint (Travis 1984) - the lexical verb fix moves into the sentence-initial complementizer position over an intervening auxiliary which is eligible for the raising and most importantly, closer to the landing site. 13b represents what is traditionally called super-raising, in which the matrix subject John moves from the deeply embedded clause and crosses an intervening subject which is closer to the matrix subject position. 13c also involves a cross-over, in violation of what is generally referred to as the Wh-island Condition.

(13) Chomsky (1995: 82)

a. "How fix $x_{i}$ [John WILL [ $t_{i}$ the car]]

b. "John $\mathbf{n}_{\mathrm{i}}$ seems [that [IP IT is certain [ $\mathrm{t}_{\mathrm{i}}$ to fix the car]]]

c. "guess [CP how h $_{\mathrm{i}}$ John wondered [WHY [we fixed the car $\mathrm{t}_{\mathrm{i}}$ ]]]

In spite of involving different types of movement, the cases in question have one thing in common, i.e., the movements all invoke a crossover. This can be nicely captured by the MLC/ACP.

In addition, once a phase derivation is completed, its complement will be transferred both to the phonological component PF and the semantic component LF and hence frozen in place in the narrow syntax, becoming inaccessible to any further operation; only the phase edge (i.e., the phase head and its specifier) is accessible to further derivations. This additional constraint is dubbed as the Phase Impenetrability Condition (PIC):

(14) The PIC (Chomsky 2001: 13)

The domain of $\mathrm{H}$ is not accessible to operations outside $\mathrm{HP}$; only $\mathrm{H}$ and its edge are accessible to such operations. 
The PIC can be illustrated by the following examples. In 15a, the embedded clause is infinitival and the embedded verb is unaccusative, with the matrix $\mathrm{CP}$ occurring as the only phase in the sentence. The phase head $\mathrm{C}$ therefore allows the matrix $\mathrm{T}$ (ense) head to agree with the DP in the embedded clause, yielding a long-distance agreement effect. In contrast, the matrix-embedded long-distance agreement effect is not attested in 15b. Unlike 15a, the embedded clause in $15 \mathrm{~b}$ is a finite $\mathrm{CP}$ and hence a phase. According to the PIC, the complement of the $\mathrm{C}$ phase head, namely, the embedded TP, is inaccessible to any further syntactic operation once the embedded $\mathrm{CP}$ is merged with the matrix verb, blocking its subject from agreeing with the matrix subject.

(15) a. [CP There are likely to be awarded several prizes]. (Chomsky 2001: 7)

b. It is said [CP that [TP we have taken bribes]. (Radford 2004: 292)

In what follows, I adopt Chomsky's phase theory to account for CA extraction asymmetries in Tsou.

\section{Extraction asymmetries}

\section{Research questions}

While there is a large amount of literature on applicatives cross-linguistically, very little attention is paid to those which apply to ditransitive verbs in Formosan languages. Holmer (1999) represents a rare exception in this regard. In that article, Holmer notes that in the Formosan language Seediq, an IA takes the transported theme of a ditransitive verb as the trigger of the sentence, as in 16a, whereas an LA chooses either a transported theme or a recipient as the trigger, as in 16b-c, respectively.

(16) Seediq (Holmer 1999: 435, glosses mine, HYC)

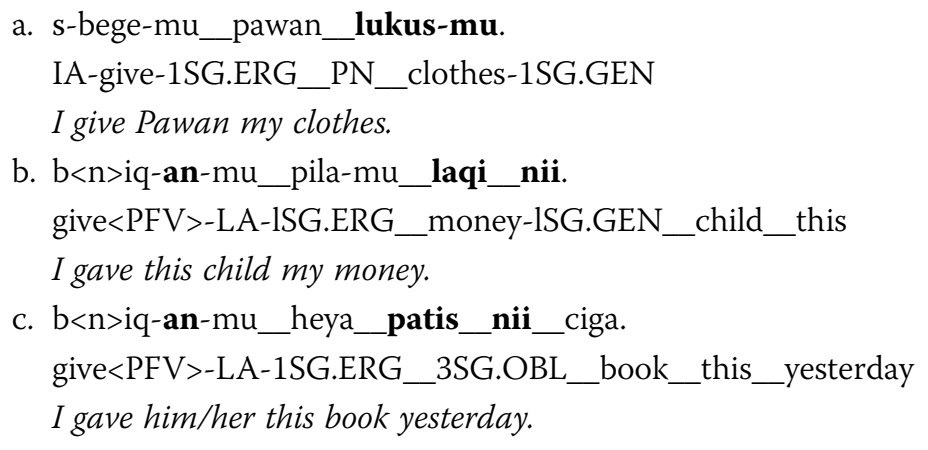

Furthermore, Holmer observes that the extraction patterns in a ditransitive construction can also be found in a causative construction. As in 17, a causative IA profiles a patient (i.e., a causand) rather than a causee as the trigger.

(17) Seediq (Holmer 1999: 427, glosses mine, HYC)

s-p-iimah-mu_pawan_sino_nii.

IA-CAUS-drink-ISG.ERG_PN_wine_this

I invite Pawan to drink this wine. 
By contrast, a causative LA may profile either a causee, as in 18a, or a causand, as in $18 \mathrm{~b}$.

(18) Seediq (Holmer 1999: 433-434, gloses mine, HYC)

a. $\mathbf{p}<\mathrm{n}>$ mah-an-mu_sino_seedaq_kiya.

CAUS $<$ PFV $>$ dink-LA-1SG.ERG_wine_person_that

I asked that person to drink wine.

b. ? p-n-mah-an-mu_seedaq_sino_nii.

CAUS-PFV-drink-LA-ISG.ERG_person_wine_this

I had someone drink this wine.

Holmer's observations hold true of Tsou applicatives, though deviations from his observations are found in Tsou LAs. Let's consider IAs first. As in Seediq, the extraction pattern in a ditransitive IA is parallel to that in a causative IA in Tsou-a ditransitive IA profiles a transported theme, as in 19a; the extraction of an IA recipient is ruled out, as in 19b.

(19) a. os-'o_f-a-eni_ta_mo'o_si_tposx

TR.RL-1SG.ERG_give-TR-IA_OBL_PN_ABS_book

I gave the book to Mo'o.

b. "os-'o_f-a-eni_ta_tposx_'o_mo'o

TR.RL-1SG.ERG_give-TR-IA_OBL_book_ABS_PN

A similar extraction pattern is found in a causative IA. As in 20a-b, it is the causand tposx 'the book', not the causee mo'o that is profiled.

(20) a. os-o_poa_f-a-eni_ta_mo'o_si_tposx

TR.RL-1SG.ERG_CAUS_give-TR-IA_OBL_PN_ABS_book

I let Mo'o give the book.

b. "os-'o_poa_f-a-eni_ta_tposx_'o_mo'o

TR.RL-1SG.ERG_CAUS_give-TR-IA_OBL_book_ABS_PN

Nonetheless, Tsou differs from Seediq in the extraction of an LA absolutive. As already illustrated in 16b-c and 18, a ditransitive/causative LA can profile either a recipient/causee or a transported theme/causand in Seediq. This is, however, not the case in Tsou. In Tsou, a ditransitive/causative LA invariably profiles a recipient, not a transported theme/ causand. As in 21a, the ditransitive LA takes as the trigger the recipient paicx; the sentence will be ruled out if the transported theme peisu is taken as the trigger, as in 21b.

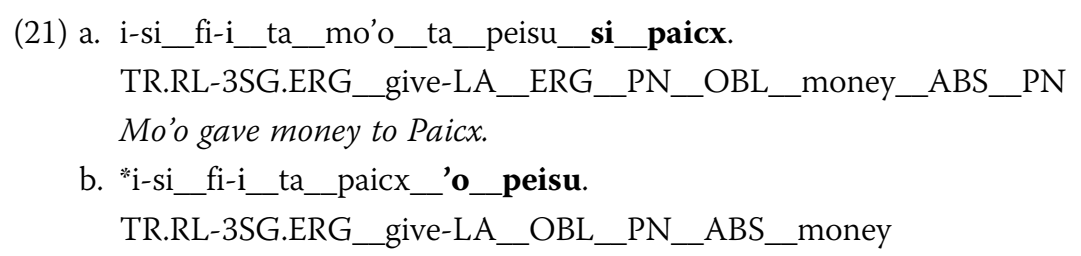

Likewise, a Tsou causative LA chooses as the trigger a recipient rather than a causand, as in 22a-b. 
(22) a. os-'o_poa_fi-i-eni_ta_mo'o_ta_peisu_si_paicx.

TR.RL-1SG.ERG_CAUS_give-LA-IA

OBL_PN_OBL_money_ABS_PN

I let Mo'o give money to Paicx.

b. "os-'o_poa_fi-i-eni_ta_mo'o_ta_paicx_'o_peisu.

TR.RL-1SG.ERG_CAUS_give-LA-IA_

OBL_PN_OBL_PN_ABS_money

It becomes clear by now that there are two types of profiling asymmetries in Tsou-a ditransitive/causative IA profiles a transported theme/causand (direct object, DO), whereas a ditransitive/causative LA profiles a recipient (indirect object, IO). An IA and an LA display an opposite profiling pattern.

There are reasons to believe that the profiling asymmetries are actually extraction asymmetries. The following example suffices to illustrate this point.

(23) os-'o_poa_p'ecihi-neni_ta_mo' $\mathbf{o}_{\mathbf{i}} \_$ne hucma_'o_iachi-si $\mathbf{i}_{\mathbf{i}} \_$ongko

TR.RL-1SG.ERG_CAUS_step(TR)-IA_OBL_PN_yesterday_ABS

self-3SG_shadow

I let Mo'o step on his own shadow yesterday.

Consider, in particular, the distribution of the reflexive iachi 'self' and the temporal adverbial ne hucma 'yesterday'. On the assumption that a temporal adverbial like 'yesterday' is merged as high as around a TP (Cinque 1999), the reflexive trigger iachisi ongko 'his own shadow' that occurs external to ne hucma must surface in or above TP. However, as a reflexive, iachi must be bound and hence c-commanded by its antecedent mo'o, which appears internal to ne hucma for the purpose of a proper interpretation. The most likely way out is for iachi to originate in a position lower than mo'o, presumably within $\nu \mathrm{P}$, and then moves to a higher position in or outside TP as the trigger. In this view, the above-mentioned asymmetries with regard to the trigger profiling are equivalent to the asymmetries of the trigger extraction, which can be summarized as Table 4:

Setting minor variations in locative applicatives aside, we can find that the extraction asymmetries are also attested in Seediq. Immediate questions arise. Why is this so? In particular, why can a transported theme/causand that originates in a deeply embedded lower position end up in the top position of the sentence without inducing any locality effects? In the subsequent sections, I attempt to answer these questions from a Minimalist phase-based perspective and focus my attention on Tsou. I believe that my proposal can carry over to other Formosan languages though.

Table 4 Extraction asymmetries in Tsou ditransitive/causative applicatives

\begin{tabular}{lll}
\hline Extraction target & IAs & LAs \\
\hline Extract DO & Yes & No \\
Extract IO & $\mathrm{No}^{\text {h }}$ & Yes \\
\hline
\end{tabular}




\section{Previous analyses}

\section{The thematic agreement account}

In the traditional Austronesian literature, applicatives are treated as part of a special focus or voice system that selects a corresponding thematic argument as the trigger: an IA is usually conceptualized as a circumstantial focus/voice that profiles as the trigger a peripheral argument such as a beneficiary, an instrument, or a reason and an LA is analyzed as a locative focus/voice that profiles as the trigger a location or a locationrelated argument (e.g. a recipient, goal, or source). In spite of its apparent descriptive advantage, this kind of thematic agreement approach runs into serious problems upon a closer inspection. As noted in Yeh (2003) and H. Chang and Yeh (2008), the so-called focus/voice system displays pervasive thematic mismatches across Formosan languages. Figure 1 gives a rough idea of what the thematic mismatches look like $(\mathrm{PF}=$ patient focus, $\mathrm{LF}=$ locative focus, IF = instrumental focus; the argument at the bottom represents the thematic role of the trigger designated by the corresponding focus/voice morphology):

The thematic agreement approach does not work out even if it intends the thematic label IA/LA for a more general cover term. In the case of IA, there is no single semantic/ conceptual denominator which can subsume all the associated thematic roles (namely, a beneficiary, an instrument, a cause, a transported theme, and a causand) under the rubric. Another more challenging fact for the thematic agreement approach is the occurrence of double transitives/applicatives. As noted in Chang (2011a), an IA can co-occur with an LA (Example 24), or with a transitive (Example 25) on the same verb in Tsou.

(24) a. os-'o_poa_fi-i-neni_ta_peisu_ta_mo'o_si_paicx.

TR.RL-1SG.ERG_CAUS_give-LA-IA_OBL_money_OBL_PN_

ABS_PN

I let Mo'o give money to Paicx.

b. te-ko-n'a_phin-i-neni_to_simeo_(na)_a'o

IRR-2SG.ERG-DT_buy-LA-IA_OBL_pork_ABS_1SG.ABS

Buy me some pork!

c. os-'o_poa_ait-i-neni_to_mo'o__o_televi

TR.RL-1SG.ERG_CAUS_look-LA-IA_OBL_PN_ABS_television

I let Mo'o watch television.

(25) a. os-'o_f-a-eni_ta_mo'o_si_tposx

TR.RL-1SG.ERG_give-TR-IA_OBL_PN_ABS_book

I gave the book to Mo'o.

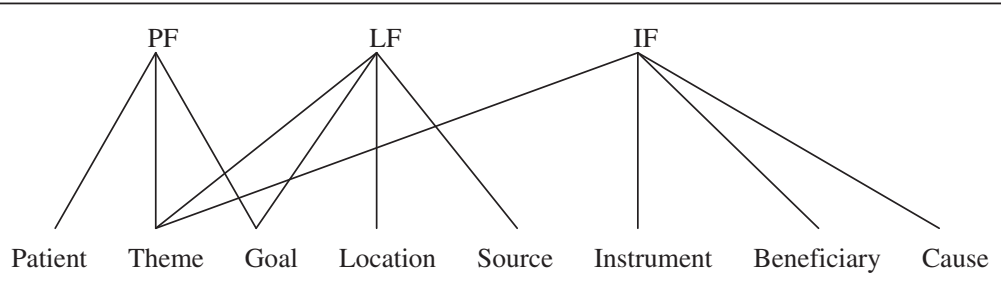

Figure 1 Thematic correspondence between focus morphology and trigger. 
b. os-'o_poa_haf-a-neni_to_paicx_'o_yungku

TR.RL.-1SG.ERG_CAUS_carry-TR-IA_OBL_PN_ABS_basket

I let Paicx carry the basket.

Incidentally, double applicatives are also attested in the Formosan language Bunun, as noted in Shi, Chaokai and Atul Manqoqo (2013). Compare:

(26) Takibakha Bunun (Shi and Manqoqo 2013, glosses mine, HYC) ${ }^{\mathrm{i}}$

a. 'is-baliv-an_zaku_ka_bali_i_hung. IA-buy-LA_1SG.ERG_ABS_PN_OBL_book

I bought Bali a book.

b. 'is-pa-simul-an_zaku_ka_bali'_i_hung. IA-CAUS-borrow-LA_1SG.ERG_ABS_PN_OBL_book

I lent Bali a book.

On the assumption that there is a thematic correspondence between the focus/voice affix and the trigger, the thematic agreement approach will predict that there should be two triggers in 24-26. This prediction is obviously incorrect, given that there is only one trigger in the sentences under discussion.

\section{The grammatical agreement approach}

Another line of agreement approach is to treat Austronesian applicative morphology as a marker of grammatical agreement that reflects the underlying syntactic position from where the trigger is derived. This is the syntactic approach that Holmer (1999) takes in his study of Seediq.

Like the traditional analysis, Holmer (1999) classifies Seediq focus/voice into four categories, namely, agent focus (AF), patient focus (PF), locative focus (LF), and instrumental focus (IF). However, unlike the traditional thematic agreement approach, he analyzes the four focus/voice categories as a system of grammatical agreement that reflects the original structural position of the trigger. Specifically, he treats a Seediq IA affix as an agreement marker on the clausal inflectional head which indicates that the third argument of a verb is promoted as the trigger. For a two-argument verb, the third argument refers to a peripheral argument which is not selected by the verb, as indicated in Figure 2 below:

For a ditransitive verb, the third argument is a transported theme, as indicated in Figure 3 below:

For a triadic causative verb, the third argument is a causand, as indicated in Figure 4:

Holmer contends that the status as a third argument motivates the use of an IA prefix $s$-, as shown below:

(27) Seediq (Holmer 1999: 426, glosses mine, HYC)
a. s-tabu-mu_dapa_sudu_nii.
IA-feed-ISG.ERG__ow_hay_this
I shall feed cows with this hay.
b. s-qalang-daha_lmiqu_ka_dapa.
IA-fence-3PL.ERG_forest_ABS_cow

They fence in (a section of) forest for the cow. 

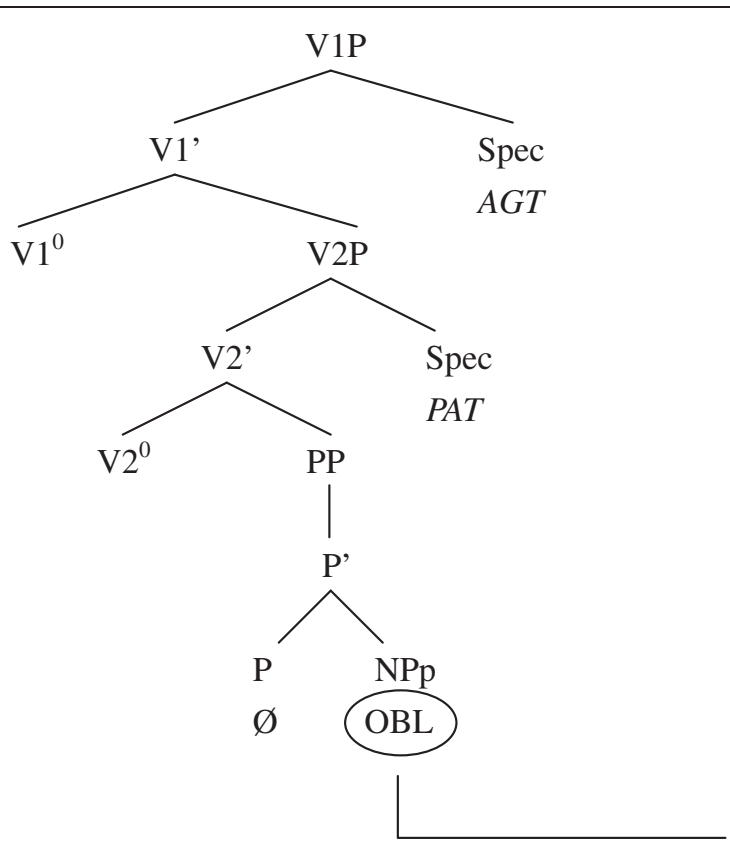

Figure 2 IF and the peripheral argument in Seediq (Holmer 1999: 439).

c. s-bege-mu_pawan_lukus-mu.

IA-give-1SG.ERG_PN_clothes-1SG.GEN

I give Pawan my clothes.

d. s-p-iimah-mu_pawan_sino_nii.

IA-CAUS-drink-ISG.ERG_PN_wine_this

I invite Pawan to drink this wine.

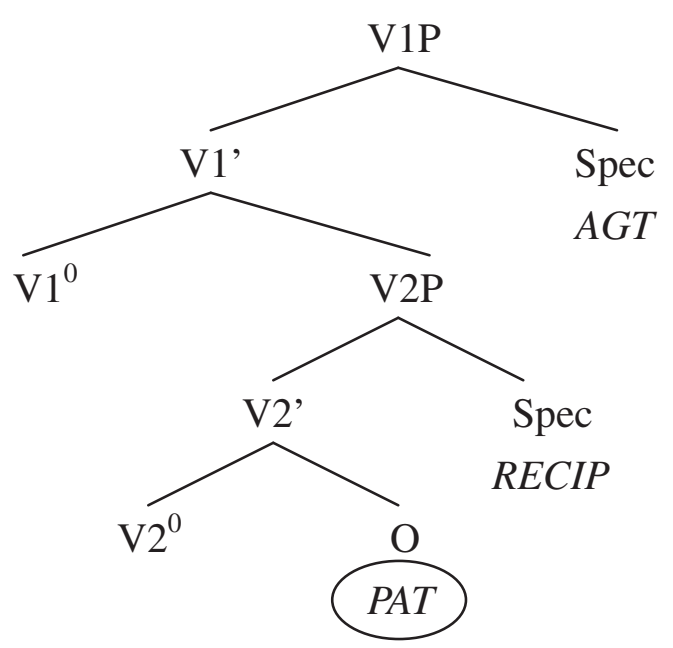

Figure $3 \mathrm{IF}$ and the transported theme in Seediq (Holmer 1999: 435). 


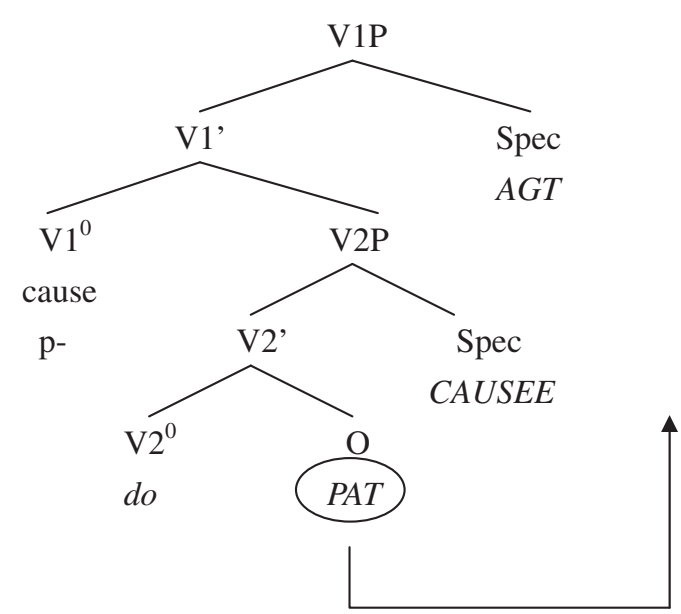

Figure 4 IF and the causand in Seediq (Holmer 1999: 433).

In the meantime, Holmer argues that an LA indicates that the trigger originates as the complement of a location-denoting preposition and moves over at least one intervening argument, as diagramed in Figure 5:

Unlike an IA, an LA in its present tense form -an almost invariably cross-refers to a locative argument, regardless of the argument structure of the verb, and hence does not make reference to the structural depth of the trigger's starting point. This can be illustrated by the following examples:

(28) Seediq (Holmer 1999: 445, glosses mine, HYC)

a. lungis-an_na_pawan_ka_pureyan.

cry-LA_ERG_PN_ABS_kitchen

Pawan cried in the kitchen.

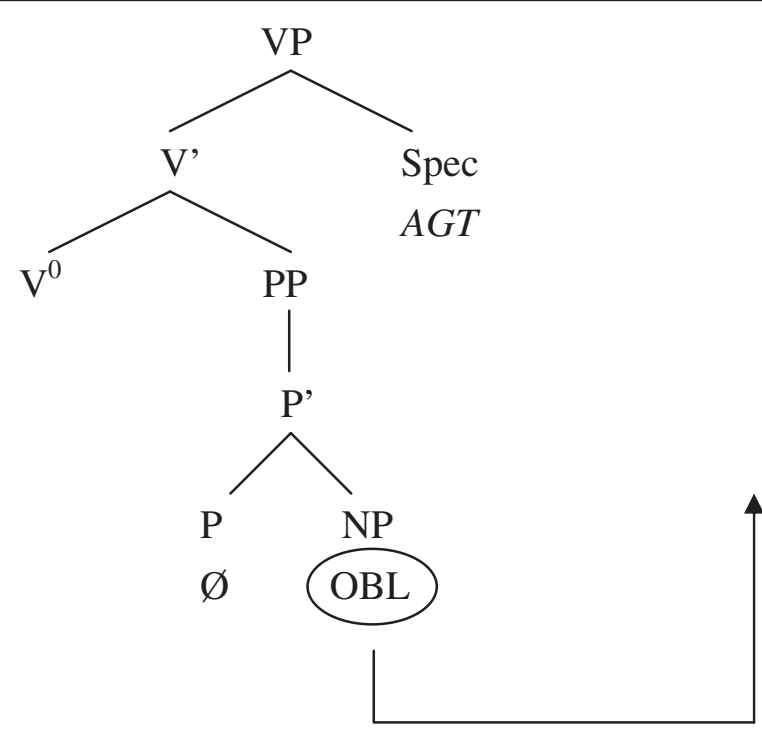

Figure 5 LF and the location in Seediq (Holmer 1999: 441). 
b. tkan-an-mu_beras_duhung_nii.

pound-LA-1SG.ERG_rice_mortar_this

I pound rice in this mortar.

While associating Seediq focus/voice morphology with the movement of the trigger, Holmer clarifies that the movement is not caused by the focus/voice morphology, but by a set of discourse factors including the definiteness and referentiality of the trigger.

If we compare Holmer's grammatical agreement approach to the traditional thematic agreement approach in the current context, we would find that the former has at least a major advantage over the latter; that is, it is exempted from the abovementioned mismatch problem in that it attributes the mismatches to a structural grouping of the trigger. However, Holmer's theory cannot evade the other problem that challenges the agreement approach in general-the manifestation of double transitives/applicatives. In the case of double transitives/applicatives, there is still only one trigger in each sentence, contra the prediction made by Holmer's grammatical agreement analysis. Moreover, Holmer's analysis leaves one of our major research questions unexplained-why can a deeply embedded argument such as a transported theme or a causand move over other intervening higher arguments without evoking any locality effects? Accordingly, we have to look for an alternative account.

\section{The case agreement approach}

Rackowski and Richards (2005) explore extractions in Tagalog under a Minimalist phase-based framework. While they are not primarily concerned with CAs, they make important claims about Austronesian focus/voice constructions and thus their analysis has strong bearing on the current discussion. Below I summarize their major points for purposes of comparison and review.

First, Tagalog promotion as the trigger patterns on a par with object shift in Scandinavian languages like Icelandic in that (i) like Icelandic shifted objects, Tagalog triggers must be specific; (ii) like Icelandic object shift, a Tagalog trigger abides by a strict locality constraint-if only one argument shifts, it must be the highest internal argument.

Second, Tagalog $v$ can either bear an EPP or not. If it does, the EPP feature on the little $v$ will attract a closest DP within its domain to its edge, creating object shift. A semantic consequence of the object shift is that the shifted object must receive a specific reading at its first landing site. The little $v$ agrees with the shifted object in Case and the Case agreement is graphically encoded on the verb in Taga$\log$, as exemplified in 29b-d below. If the little $v$ does not bear an EPP feature, object shift will not be attested; the external argument, as the highest argument of all, will be advanced as the trigger and control the verbal morphology, as in 29a below.

(29) Tagalog (Rackowski and Richards 2005: 566)

a. b<um>ili_ang_bata_ng_tela_sa_palengke_para_sa_nanay. buy $<\mathrm{NOM}>$ _ANG_child_CS_cloth_DAT_market_for_DAT_ Mother

The child bought cloth at the market for Mother. 
b. b<in $>$ ili- $\boldsymbol{\phi} \_$ng__bata_ang_tela_sa_palengke_para_sa_nanay.

buy $<\mathrm{ASP}>-\mathrm{ACC} \_\mathrm{CS} \_$child_ANG_cloth_DAT_market

for_DAT_Mother

The child bought the cloth at the market for Mother.

c. b<in>ilh-an_ng_bata_ng_tela_ang_palengke_para_sa_nanay.

buy $<$ ASP $>-D A T \_C S \_$child_CS_cloth_ANG_market_for_

DAT_Mother

The child bought (the) cloth at the market for Mother.

d. i-b<in>ili_ng_bata_ng_tela_sa_palengke_ang_nanay.

$\mathrm{OBL}-\mathrm{buy}<\mathrm{ASP}>$ _CS_child_CS_cloth_DAT_market_ANG_Mother

The child bought (the) cloth at the market for Mother.

Third, examples like 29c-d differ from those in 29a-b in that they additionally involve applicative constructions. This explains why various peripheral arguments in relation to the verb can be promoted as the trigger in Tagalog. For instance, example 29d hosts an instrumental applicative in which the beneficiary is merged as the highest internal argument within the $v \mathrm{P}$ and hence eligible for object shift via the phase edge of $v \mathrm{P}$ to the trigger of the sentence, as partially diagramed in Figure 6:

Moreover, Rackowski and Richards observe that in Tagalog, an applied object is required to undergo object shift. They attribute the requirement to a more general syntactic pattern across many languages, including English.

I am largely in line with Rackowski and Richards's phase-based account, but I have reservations for their Case agreement analysis. Their phase-based account explains nicely how and why an argument raises in a successive-cyclic manner to the top position of the sentence. However, I am skeptical of their Case agreement analysis for a number of reasons. First, it is unclear to me why the verb can agree with the applied object in an instrumental applicative. According to Rackowski (2002: 110), the applied object receives an inherent oblique case from the applicative head ApplH. In this analysis, the applied object should be inactive and thus ineligible for any syntactic operations including Agree, in accordance with Chomsky's Active/Local Goal Principle. Consider:

(30) Active/Local Goal Principle (Chomsky 2000: 123)

Movement and Agree requires a Goal that is both local and active.

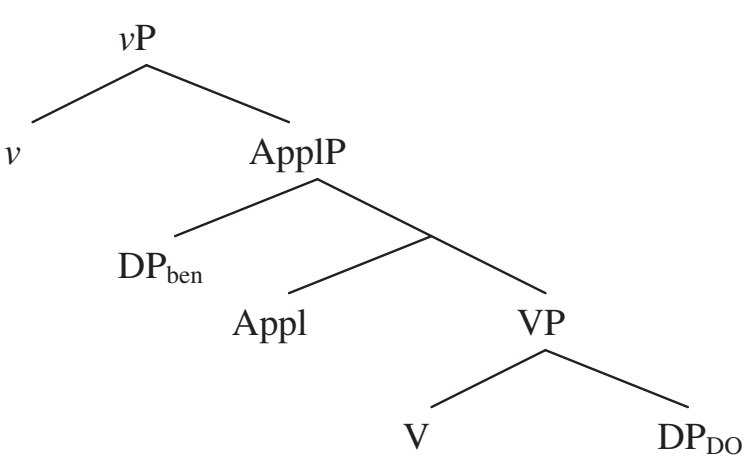

Figure 6 Beneficiary shifts in Tagalog high applicative (Rackowski and Richards 2005: 574). 
Second, their analysis does not account for why there is an EPP feature on the $v$ in constructions like 29b-d but not in those like 29a. Third, their analysis fails to give a satisfactory non-arbitrary answer to the question why an applied object is required to shift in Tagalog. Note that a stationary applied object is widely attested across many languages. In English, for example, an applied object remains in object position after the verb, as in 31 :

(31) Mary baked him a cake.

Likewise, an applied object occurs post-verbally as an object in the Bantu language Chichewa, as in 32a; advancing it to the subject position requires an additional syntactic operation of passivization, as in $32 \mathrm{~b}$.

(32) Chichewa (Tallerman 1998: 194)

a. Kalulu_a-na-gul-ir-a_mbidzi_nsapato.

hare_SU-PAST-buy-APPL-ASP_zebras_shoes

The hare bought shoes for the zebras.

(i.e. The hare bought the zebras shoes).

b. Mbidzi_zi-na-gul-ir-idw-a_nsapato_(ndi_kalulu).

zebras_SU-PAST-buy-APPL-PASS-ASP_shoes_by_hare

The zebras were bought shoes by the hare.

This also holds true of the Austronesian language Indonesian. Compare:

(33) Indonesian (Based on Cole and Son 2004: 341, 362)
a. Dia_meng-goreng-kan_saya_ayam
3SG_meN-fry_-APPL_1SG_chicken
He fried me chicken.
b. Saya_di-goreng-kan_ayam
1SG_PASS-fry-APPL_chicken
I was fried chicken.

In terms of the obligatory promotion of an applied object, Tagalog differs systematically and significantly from English, Chichewa and even Indonesian. Rackowski and Richards's account fails to capture this typological division.

Last but not least, their Case agreement analysis faces the same challenges as the grammatical agreement approach; the most challenging fact is the occurrences of double transitives/applicatives in Tsou and Bunun.

\section{The ergative/light-verb analysis}

Like Rackowski and Richards (2005), Aldridge (2004, 2005, 2008a, b) also adopts a Minimalist phase-based account of Austronesian focus/voice. However, Aldridge's approach differs from Rackowski and Richards's in two important respects. First, she regards Tagalog as an ergative rather than an accusative language. Accordingly, in her account, case is marked on an ergative-absolutive basis instead of a nominativeaccusative basis in Tagalog; constructions like 29a above are treated as antipassives and 
those like 29b-d above as transitives. Second, she analyzes Austronesian focus/voice system as a set of light verb. In her view, constructions like 29a have an intransitive light verb that does not form a phase head and bear no EPP and Case features; by contrast, constructions like 29b-d have a transitive light verb that constitutes a phase head and carries an absolutive Case feature, which values the closest internal argument, and an EPP feature, which triggers the movement of the highest internal argument to the edge of the transitive $v \mathrm{P}$. The example in $29 \mathrm{~b}$ will have a phrase structure like (Figure 7):

For constructions like 29c-d, she assumes with Rackowski and Richards (2005) that the transitive light verb takes an additional applicative projection as its complement, allowing its applied argument to occur as the highest internal argument for Case checking and extraction, as diagramed in (Figure 8):

Aldridge's ergative/light-verb approach is basically successful. It accounts for most of the problems facing the above-mentioned analyses. It explains nicely the presence/absence of a formal feature on the light verb. The light verb in constructions like $29 \mathrm{~b}-\mathrm{d}$ has an EPP feature and a Case feature because it is ergative/transitive, as opposed to the light verb in constructions like 29a which is antipassive/intransitive and thus entertains no such features. This division follows directly from Chomsky's phase theory. Her analysis also explains the obligatory advancement of an applied object in Tagalog. Given that applicatives are inherently transitive and that transitive light verbs must have an EPP feature in an ergative language, it is expected that an applied object, which occurs as the highest internal argument, should move to the edge of its c-commanding $v \mathrm{P}$.

Still, it is unclear how she accounts for the research questions we put forward in section Research questions. In particular, how can her account explain the raising of a deeply embedded argument such as a transported theme and a causand? Also, how can she accommodate double transitives/applicatives in Tsou and Bunun?

In view of the shortcomings of the previous accounts, I shall offer an alternative analysis, especially, in order to account for the extraction asymmetries presented in section Research questions.

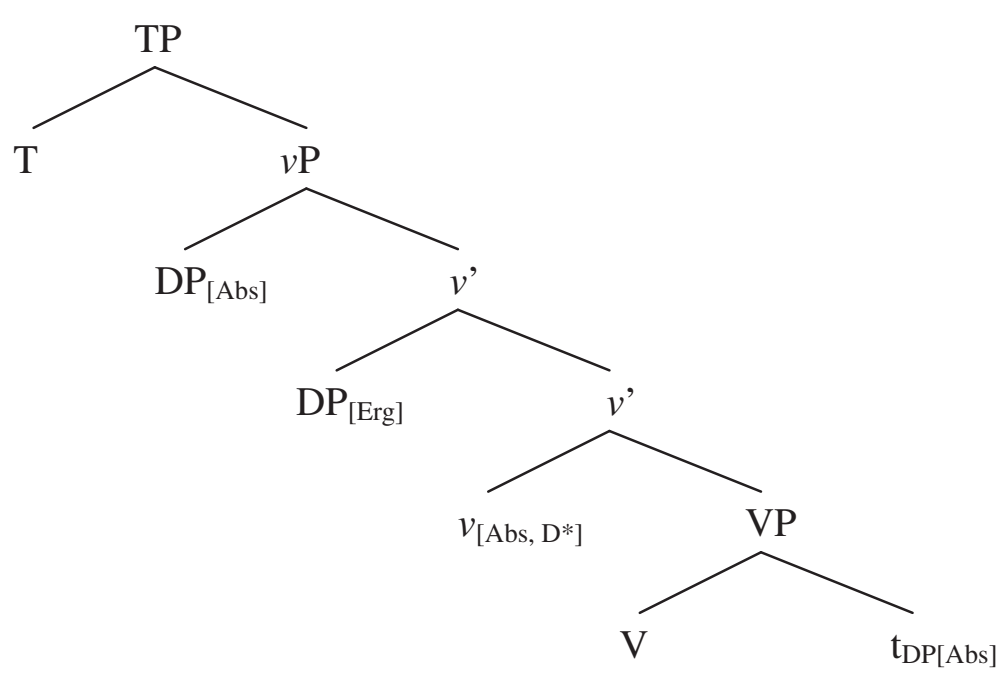

Figure 7 Extraction in Tagalog transitive (Aldridge 2008a, 2008b: 1445). 


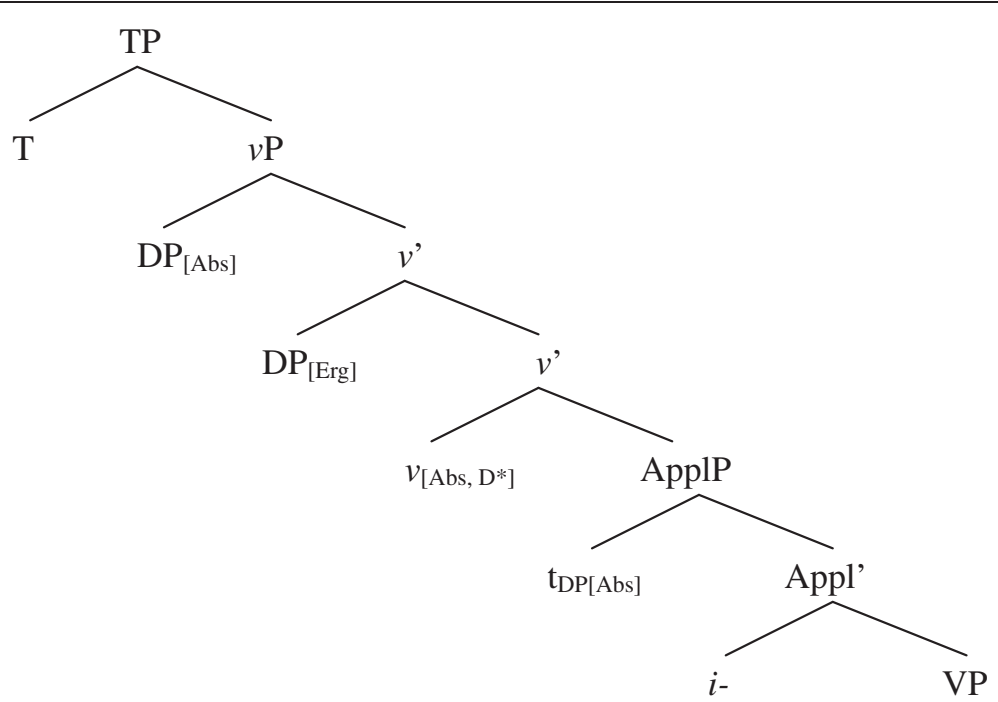

Figure 8 Extraction in Tagalog applicatives (Aldridge 2008a, 2008b: 1445).

\section{Phase theory of applicatives}

The background

McGinnis's phase account of applicatives

In light of Chomsky's phase theory, McGinnis (2001, 2008) ties extraction possibilities to the Pylkkänen-style high-low applicative distinction. In her view, a high applicative takes an indirect object (IO) as its specifier and a VP as its complement, as schematized in Figure 9:

In contrast, a low applicative takes an IO as its specifier and a direct object (DO) as its complement, as diagramed in Figure 10:

Her proposal is that a high applicative heads a phase, but its low counterpart does not. Being a phase, a high applicative opens up its outer specifier as an escape hatch and allows a lower object (the DO in Figure 9) to leapfrog via the escape hatch the higher object (the IO in Figure 9) in its inner specifier without violating any locality constraint. In contrast, no such an option is available in a low applicative-being nonphasal, a low applicative is without an escape hatch and thus allows only the extraction of a higher object. This distinction explains the A-movement possibilities in applicatives across many languages. Consider the symmetrical language Kinyarwanda for example: A lower object as well as a higher object can be passivized as the subject in a

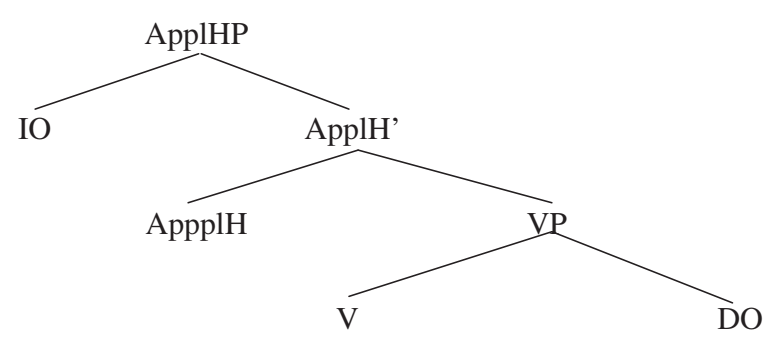

Figure 9 High applicative (McGinnis 2001: 106). 


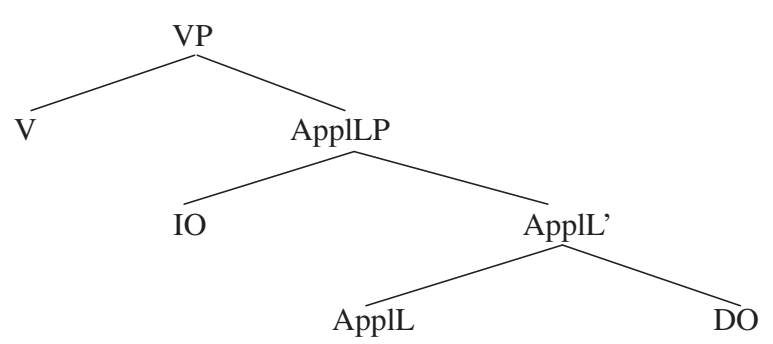

Figure 10 Low applicative (McGinnis 2001: 106).

high benefactive applicative, as in 34a-b; however, a higher object, but not a lower object, can be promoted as the subject in a low recipient applicative, as in 35a-b.

(34) Kinyarwanda (McGinnis 2001: 107)

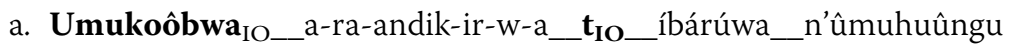

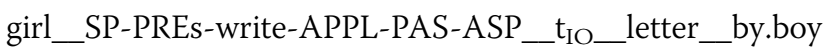

The girl is having the letter written for her by the boy.

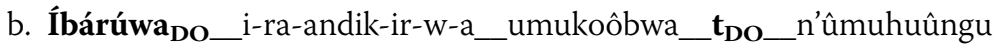
letter_SP-PREs-write-APPL-PAS-ASP_girl_t $t_{I O}$ _by.boy

The letter is written for the girl by the boy.

(35) Kinyarwanda (McGinnis 2001: 107)

a. Ishuûri ${ }_{I O} \_$ry-oohere-j-w-é-ho_tt school_SP-send-ASP-PAS-ASP-LOC_book_by.teacher The school was sent the book by the teacher.

b. "Ishuûri book_SP-send-ASP-PAS-ASP-LOC_school_by.teacher The book was sent to school by the teacher.

Although the IA-LA distinction is not a high-low applicative dichotomy in Tsou (see section Dispensing with the high-low applicative distinction), McGinnis's idea of linking the structural status of an applicative to its extraction possibility is useful for the current discussion. In light of this, we shall explore the question of whether the CAs' extraction asymmetries presented in section Research questions can be attributed to their structural properties.

\section{Causatives}

In Tsou, causativization plays a critical role in the syntactic operations of double transitives/applicatives and thus deserves a brief introduction.

Tsou employs two overt grammatical morphemes to encode causativization. The first one is a causative prefix $p a-$. Note, however, that unlike many other Formosan languages, the causative prefix $p a$ - is not productive in Tsou; specifically, $p a$ - is limited to a bunch of transitive verbs such as pa'cohivi 'teach, tell', pai'usni 'send', pahaf(a)neni 'cause to carry', etc.

The other one is a light verb poa. Unlike pa-, poa is pervasive and productive. It occurs as a free-standing light verb rather than as a prefix. This is evidenced by the fact 
that poa and the stem verb can be intervened by an adverbial verb or a negator, as in $36 \mathrm{a}-\mathrm{b}$.

(36) a. os'o_poa_iachi-a_haf-a-neni_to_paicx_o_o_yungku

TR.RL-1SG.ERG_CAUS_oneself-TR_carry-TR-

IA_OBL_PN_ABS_basket

I let Paicx carry her own basket.

b. o.s'o_poa_o'te_haf-a-neni_to_paicx_'o_yungku

TR.RL-1SG.ERG_CAUS_NEG_carry-TR-IA_OBL_PN_ABS_basket

I did not let Mo'o carry the basket.

In spite of being morphologically distinct, poa and $p a$ - behave alike in several respects. First, both of them are used exclusively in grammatically transitive constructions, as evidenced by the fact that they pattern with a transitive mood auxiliary, but not with an intransitive one. Consider:

(37) a. i-si/"mi-ta_poa_an-a-neni_ta_oko_si_f'ue.

TR.RL-3SG.ERG/INTR.RL-3SG.ABS_CAUS_eat-TR-

IA_OBL_child_ABS_sweet.potato

He let a child eat the sweet potatoes.

b. i-si/“mi-ta_poa_ma-hafo_to_yungku_o_o_mo'o.

TR.RL-3SG.ERG/INTR.RL-3SG.ABS_CAUS_INTR-

carry_OBL_basket_ABS_PN

He let Mo'o carry a basket.

(38) i-si/"mi-ta_pa-cohiv-i_si_mo'o.

TR.RL-3SG.ERG/INTR.RL-3SG.ABS_CAUS-aware-LA_ABS_PN

He taught Mo'o.

Second, they are eligible for turning a transitive verb to a ditransitive one, thereby enabling the advancement of a deeply embedded direct object as the trigger. Take a transitive verb haf- 'carry' for example. With the support of an IA suffix -(n)eni, a beneficiary is introduced to the event of carrying and promoted as the trigger:

$$
\begin{aligned}
& \text { os-'o__haf-neni_to_yungku__o__paicx } \\
& \text { TR.RL-1SG.ERG_carry-IA_OBL_basket_ABS_PN } \\
& \text { I carried a basket for Paicx. }
\end{aligned}
$$

In contrast, upon causativization, either through the prefixation of $p a$ - or the introduction of poa, the causand of the caused carrying event is promoted as the trigger instead. Compare:

(40) a. os-'o_pa-haf-a-neni_to_paicx__o_yungku

TR.RL-1SG.ERG_CAUS-carry-TR-IA_OBL_PN_

ABS_basket

I let Paicx carry the basket. 
b. os-'o_poa_haf-a-neni_to_paicx_'o_yungku

TR.RL-1SG.ERG_CAUS_carry-TR-IA_OBL_PN_ABS_basket

I let Paicx carry the basket.

In view of the syntactic parallelisms and other reasons that will become obvious in the subsequent sections, I assume that poa-CAs and pa-CAs share an underlying structure, with poa and $p a$ - each realizing a distinct light verb. In poa-CAs, poa occurs as a transitive little $v$, which bears an EPP feature while taking as its complement a functional projection that contains a causative $v \mathrm{P}$ headed by a phonologically null element comparable to $p a$-. The diagram below schematizes a partial underlying structure of poa-CAs.

(41) $\left[{ }_{\nu \mathrm{P}}\left[\right.\right.$ poa $\left.\left.\left.\left[\mathrm{ApplHP}-(n) e n i\left[{ }_{\nu \mathrm{P}}\left[v^{\prime} \phi-\ldots[\mathrm{VP}]\right]\right]\right]\right]\right]\right]$

The same structural characterization carries over to pa-CAs with only a slight phonological modification. In pa-CAs, the top transitive little $v$ is a phonologically null element comparable to poa, as diagramed below.

(42) $\left[{ }_{v \mathrm{P}}\left[\phi\left[\mathrm{ApplHP}-(n) e n i\left[{ }_{\nu \mathrm{P}}\left[v^{\prime} p a-\ldots . .[\mathrm{vP}]\right]\right]\right]\right]\right]$

Note that in either case, the causative prefix $p a / \phi$ - applies before an IA suffix - $(n) e n i$ in the derivation. This explains why in other Formosan languages constructions that are functionally and structurally comparable to $40 \mathrm{~b}$ display the affix order of a causative prefix occurring internal rather than external to an IA prefix, as illustrated below.

(43) Seediq (Holmer 1999: 427, glosses mine, HYC)

s-p-iimah-mu_pawan_sino__nii.

IA-CAUS-drink-ISG.ERG_PN_wine_this

I invite Pawan to drink this wine.

(44) Paiwan (Chaolin Li, personal communication)

si-pa-veli_ni_camak_a_vavuy_tjay_palang.

IA-CAUS-buy_ERG_PN_ABS_wild.pig_OBL_PN

Camak sold the wild pig to Palang.

This analysis also accommodates nicely a causative-ditransitive parallelism widely observed in Tsou and other Formosan languages, a topic to which we shall return shortly.

\section{Extractions in IAs}

\section{Complementary distribution of IA functions}

It has been demonstrated in the preceding sections that an IA may promote as the trigger a transported theme/causand or a(n) beneficiary/instrument in Tsou and Seediq, which Holmer identifies as "the third argument." Relevant examples are repeated below as 45 , where a transported theme/causand is advanced as the trigger, and as 46 , where $\mathrm{a}(\mathrm{n})$ beneficiary/instrument is advanced as the trigger. 
(45) a. os-'o_f-a-eni_ta_mo'o_si_tposx (Transported Theme)

TR.RL-1SG.ERG_give-TR-IA_OBL_PN_ABS_book

I gave the book to Mo'o.

b. os-'o_poa_haf-a-neni_to_paicx_o_oyungku (Causand)

TR.RL.-1SG.ERG_CAUS_carry-TR-IA_OBL_PN_ABS basket

I let Paicx carry the basket.

(46) a. os-o_teoc-neni_to_evi si_paicx (Beneficiary)

TR.RL-1SG.ERG_chop-IA_OBL_tree_ABS_PN

I chopped trees for Paicx.

b. os-'o_tpos-neni_to_tposx_'o_'empicu (Instrument)

TR.RL-1SG.ERG_write-IA_OBL_letter_ABS_pencil

I wrote a letter with the pencil.

In 46, the IA performs the typical applicative function by introducing a peripheral argument to the event described by the verb. A standard theory of applicative suffices to account for its behavior-the applied object is merged in the specifier of the applicative projection which is situated between a $v \mathrm{P}$ and a VP; as the highest internal argument, it is attracted to the top position of the sentence by the ccommanding functional heads with uninterpretable features. In contrast, the case in 45 is not that straightforward. Note that the trigger is an argument semantically selected by the base verb in 45; unlike a peripheral argument, it does not need to be introduced by an applicative head in the canonical sense. From this perspective, a Tsou IA arguably performs two distinct functions: it functions as a typical argument-introducing applicative in examples like 46, dubbed as the I-function ('I' for 'instrument') on the one hand and as an atypical argument-licensing applicative in examples like 45, labeled as the T-function ('T' for 'transported theme'). In view of this functional distinction, one may want to distinguish two types of IAs structurally, with its I-funciton projected as a thematic applicative and its T-function as an expletive applicative $e^{j}$. However, this move leaves two important questions unanswered: (i) What is the motivation underlying the thematic-expletive distinction? (ii) Why do a thematic applicative and its expletive counterpart share the same applicative morphology consistently?

It is important to point out that an I-function and its T-function counterpart are basically in complementary distribution. A T-function applies only to ditransitive predicates, whereas an I-function applies elsewhere, as formulated in 47.

(47) T-function and I-function in complementary distribution

An IA advances a transported theme/causand as the trigger if it applies to a ditransitive verb (T-function); otherwise, it advances a(n) beneficiary/instrument as the trgger (I-function).

It should be clarified that a ditransitive verb here can be either an inherently triadic verb (e.g. faeni 'give' in 45a) or a morphosyntactically derived ditransitive one (e.g. poa haf(a)neni 'cause to carry' in 45b). The I-T functional split is very useful in teasing apart the following minimal pair of IA sentences: 
(48) a. os-'o_haf-neni_to_yungku_'o_paicx (I-function)

TR.RL-1SG.ERG_carry-IA_OBL_basket_ABS_PN

I carried a basket for Paicx.

b. os-'o_pa-haf-a-neni_to_paicx_'o_yungku (T-function)

TR.RL-1SG.ERG_CAUS-carry-TR-IA_OBL_PN_ABS_basket

I let Paicx carry the basket.

Sharing the same verb root, the examples in 48a-b make a minimal morphological distinction in the presence/absence of the causative prefix $p a$-. With it, the sentence renders a theme as the trigger, as in the b-example; without it, the sentence renders a beneficiary as the trigger, as in the a-example. In other words, the IA carries out an I-function in the a-example but a T-function in the b-example. The I-T functional split correlates closely with the argument structure of the base verb-an I-function is associated with a transitive verb but its T-function counterpart with a ditransitive verb, as nicely predicted by the generalization in 47 .

The complementary distribution of an IA's I-T function is widely attested across Formosan languages. This is found in Seediq, as already presented in section The grammatical agreement approach. Compare also Mayrinax Atayal (Example 49) and Northern Paiwan (Example 50). The IA prefix si- in Mayrinax Atayal and Northern Paiwan is functionally equivalent to the IA suffix -(n)eni in Tsou. Like -(n)eni, si- performs an I-function when attached to a dyadic verb (Exmaples 49-50a, b), but a T-function when attached to a ditransitive predicate (Exmaples 49-50c, d).

(49) Mayrinax Atayal (Chunming Wu, personal communication)

a. si-qaniq_ni'_watan_cu'_mami'_ku'_qaquway (Instrument)

IA-eat_ERG_Watan_OBL_cooked.rice_ABS_chopsticks

Watan ate cooked rice with the chopsticks.

b. si-qaniq_ni'_watan_cu'_mami'_i'_tapas (Beneficiary)

IA-eat_ERG_Watan_OBL_cooked.rice_ABS_Tapas

Watan ate cooked rice for Tapas.

c. si-baiq_ni'_watan_i'_tapas_ku'_pila' (Transported Theme)

IA-give_ERG_Watan_OBL_Tapas_ABS_Money

Watan gave the money to Tapas.

d. si-pa-nubuag_ni'_watan_'i'_tapas_ku'_qusia' (Causand)

IA-CAUS-drink_ERG_Watan_OBL_Tapas_ABS_water

Watan caused Tapas to drink the water.

(50) Northern Paiwan (Chunming Wu, personal communication)

a. ku-s<in>i-kan_tua_kinsa_a_kisi (Instrument)

1S.ERG-IA $<$ PFV $>$-eat_OBL_cooked.rice_ABS_bowl

I have eaten cooked rice with the bowl.

b. ku-si-ekel_ti_kavakaw (Beneficiary)

1S.ERG-IA-run_ABS_Kavakaw

I ran for Kavakaw.

c. ku-si-pavay_tjay_palang_a_paisu (Transported Theme)

1S.ERG-IA-give_OBL_Palang_ABS_money

I gave the money to Palang. 


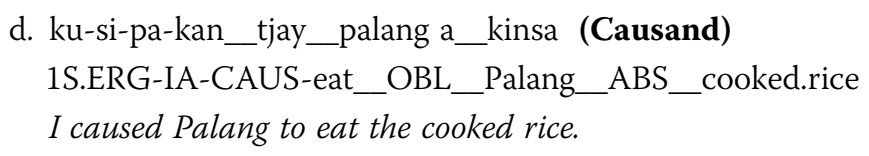

This does not seem to be language-specific. A similar pattern is found across many genetically unrelated languages. In English, for example, the preposition with marks an instrument when co-occurring with a transitive verb (Example 51a); it marks either a transported theme (Example 51b) or a causand (Example 51c) in collocation with a ditransitive verb.

(51) a. John cut the meat with a knife. (Instrument)

b. The judge presented the winner with a prize. (Transported Theme)

c. We fed the horses with apples, oats, and hay. (Causand)

The same observation holds of the case suffix -nik in West Greenlandic (Example 52) and the preposition $n e$ in Balungo (Example 53).

(52) West Greenlandic (Newman 1996: 105)
a. Nanuq_savim-mi-nik_kapi-vaa. (Instrument)
Polar.bear_knife-his-INST_stab:3SGSUBJ:3SGOBJ-Indicative
He stabbed the polar bear with his knife.
b. Niisi_aningaasa-nik_tuni-vaa. (Transported Theme)
Niisi_money-INST:PL_give:3SGSUBJ:3SGOBJ-Indicative
He gave Niisi money.

(53) Babungo (Scaub 1985: 64, 60)
a. nwé_sàn_z ẑ̃ _nà_mbàỳ. (Instrument)
he_beat:PERF_snake_with_walking_stick
He has beaten a snake with a walking stick.
I_give:PERF_Lambi_with_thing
I gave something to Lambi.
b. Mà_kò_Làmbí_nà_fá. (Transported Theme)

As argued in Newman (1996), the pervasive shared marking of a transported theme with an instrument is cognitively motivated-both of them are handled by an agent in performing an action. This is conceptualized in the following schema:

The cognitive explanation is faithfully realized in the distribution of the preposition 以 $y i$ 'with' in Archaic Chinese. Like the English preposition with, yi marks a transported theme/causand of a ditransitive verb and the instrument of a transitive verb. Compare:

(54) Archaic Chinese (列女傳/第二卷 賢明傳/第十四篇 楚老萊妻)

a. 可随以鞭捶

$$
\begin{aligned}
& \text { ke_sui_yi_bianchui (Instrument) } \\
& \text { can_follow_with_whip }
\end{aligned}
$$

You can hit him with a whip subsequently. 
b. 可授以官祿者

ke_shou_yi_guanlu_zhe (Transported Theme)

can_give_with_official.post_NMLZ

those who can be given an official post

c. 可食以酒肉者

ke_si_yi_jiourou_zhe (Causand)

can_feed_with_feast_NMLZ

those who can be fed with a feast

('Wife of Lao Lai of Chu', Book 2 'The Worthy and Enlightened', Lienu Zhuan)

Interestingly, on the basis of deciphering the Oracle, we learn that $y i$ evolved from a verb meaning 'hold/carry/bring an object' (郭锡良 Kuo 1998). In this sense, the event of hitting someone with a whip in 54a has a literal interpretation of holding a whip in hitting someone and the event of giving someone an official post in 54b will translate literally into the event of holding an official post in carrying out the donation. This mimics Newman's schematic conceptualization in Figure 11.

On the assumption that an applicative results from the incorporation of a preposition/ case marker into the verb (Baker 1988), we can treat an IA's I-T functional pair in Tsou, Seediq, Atayal, and Paiwan on a par with a preposition's instrument-transported theme/ causand functional pair in English, Archaic Chinese, West Greenlandic, and Balungo and extend Newman's cognitive account of the prepositional marking to IAs in Tsou. In light of the cross-linguistically well-attested complementary distribution of an instrumental function and a transported theme/causand function and the cognitively well-motivated instrumental marking of a transported theme/causand, I argue that an IA in its T-function is syntactically projected in the same way as an IA in its I-function (namely, as an ApplP) and that a transported theme/causand is merged in the same position as an instrument/ beneficiary (i.e., in SpecApplP). We shall return to this shortly.

\section{Extraction uniformly from the specifier of an IA}

The above-mentioned complementary distribution of an IA's I-function and its Tfunction suggests that they are two variants of a syntactic entity. Given the applicative nature of an IA in its I-function, the shared syntactic entity should be an applicative phrase (ApplP). On the assumption that applicatives are consistently high in Tsou, as already argued in section Dispensing with the high-low applicative distinction, the shared ApplP should be a high ApplP, merged under a $v \mathrm{P}$ and above a VP. The widely

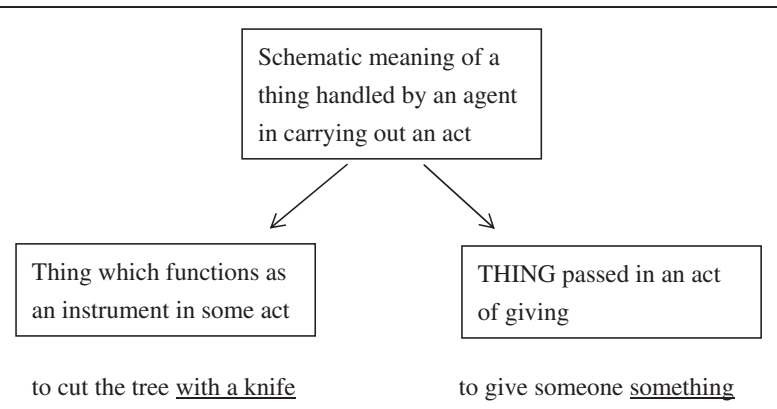

Figure 11 West Greenlandic instrumental case (Newman 1996). 
spread instrumental marking of a transported theme/causand further suggests that like an instrument, a transported theme/causand should also be base-generated in SpecApplP in an IA. Let's consider the typical IA first.

\section{(i) IO extraction}

We have shown above that an IA advances a(n) beneficiary/instrument as the trigger when applying to a transitive verb. If we adopt McGinnis's terminology, we can label the applied beneficiary/instrument that undergoes the advancement as the indirect object (IO). Exampes of this sort are repeated below as 55 .

(55) a. os-'o_teoc-neni_to_evi_si_paicx

TR.RL-1SG.ERG_chop-IA_OBL_tree_ABS_PN

I chopped trees for Paicx.

b. os-'o_tpos-neni_to_tposx_'o_'empicu

TR.RL-1SG.ERG_write-IA_OBL_letter_ABS_pencil

I wrote a letter with the pencil.

Note that the base verbs teoc 'chop' and tpos 'write' are transitive rather than ditransitive verbs here. Unlike those IAs which are based on a ditransitive verb, the IAs in question cannot advance a direct object (DO). Compare:

(56) a. "os-'O_teoc-neni_to_paicx_si_evi

TR.RL-1SG.ERG_chop-IA_ERG_PN_ABS_tree

b. "os-'o_tpos-neni_to_'empicu_'o_tposx

TR.RL-1SG.ERG_write-IA_OBL_pencil_ABS_letter

In this regard, Tsou differs sharply from Kinyarwanda. It has been shown in section McGinnis's phase account of applicatives that in Kinyarwanda, a high applicative can advnce either an IO or a DO. The disparity does not seem to be accidental; it follows from a general typological division: Tsou is an asymmetrical object language, as pointed out in $\mathrm{H}$. Chang (2011b), whereas Kinyarwanda is a symmetrical object language (Bresnan and Moshi 1990).

Recall also that McGinnis analyzes a Kinyarwanda high applicative as a phase, hence enabling a lower object to move over a higher object. Along this line of thought, the IAs in 55 do not form a phase by themselves, thus disallowing the DO to leapfrog the IO. The syntactic structures of IAs such as 55 are likely to be very simple, with an ApplP dominated by a transitive $\nu \mathrm{P}$, and their derivations can be very straightforward and proceed in the way characterized by Aldridge (see section The ergative/light-verb analysis). Given that Tsou is an ergative language, the transitive $v$ in question must constitute a phase and bears an EF. To delete its EF, the transitive $v$ attracts to its edge a closest object, which is the IO merged in SpecApplP. Accordingly, the phase one derivation of 55a can be schematized as follows:

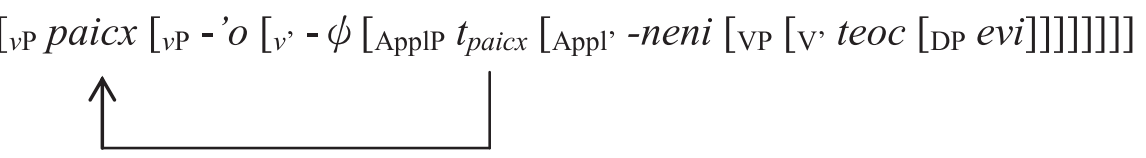


In this structure, the extraction of the DO will violate the MLC, since the DO and the transitive $v$ are intervened by the $\mathrm{IO}$, as roughly represented in 58 :

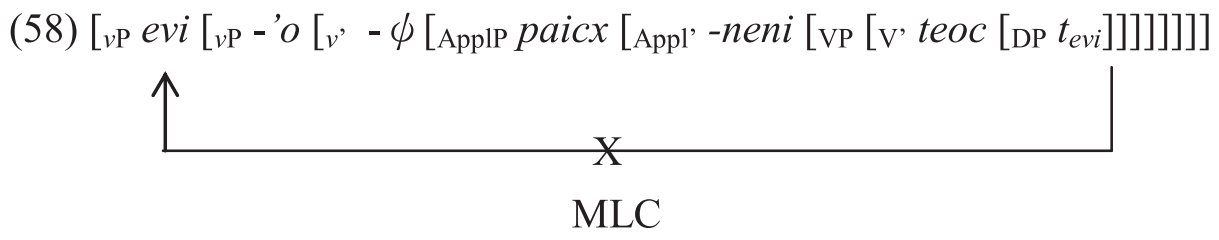

This explains why the examples in 56 are ungrammatical. To advance the DO of a transitive verb like teoc 'chop', Tsou employs a plain transitive device, as exemplified in 59a. There is no intervening IO in 59a; the DO occurs as the internal argument closest to the transitive $v$, thus eligible for being advanced to its edge, as represented in 59b.

(59) a. i-si_teoc-a_to to paicx_si_evi

TR.RL-3SG.ERG_chop-TR_ERG_PN_ABS_tree

Paicx chopped the tree.

b. $\left[v \mathrm{P}\right.$ evi $\left[v \mathrm{P}\right.$ paicx $\left[v,-a\left[\mathrm{vP}\left[\mathrm{v}\right.\right.\right.$, teoc $\left.\left.\left.\left.\left.\left.\left[\mathrm{DP} t_{\text {evi }}\right]\right]\right]\right]\right]\right]\right]$

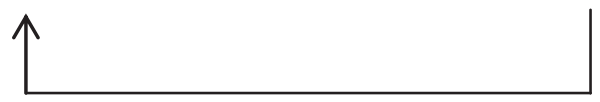

In the meantime, there are head movements involved in 55 as well. Take 55a for illustration. The big $\mathrm{V}$ teoc left-adjoins to the applicative head -(n)eni first and then moves further up to combine with the null transitive suffix $-\phi$ (a silent variant of $-a$ ), yielding the verb complex teocneni. This extends Example 57 to Example 60.

(60) $\left[{ }_{\mathrm{vP}}\right.$ paicx $\left[\mathrm{vP}\right.$ - 'o $\left[{ }^{\prime}\right.$ teoc-neni- $\phi\left[\right.$ ApplP $t_{\text {Paicx }}\left[\mathrm{Appl}\right.$ ' $t_{\text {teoc-neni }}\left[\mathrm{vP}\left[\mathrm{v}, t_{\text {teoc }}[\mathrm{DP}\right.\right.$ evi $\left.\left.\left.\left.\left.\left.]\right]\right]\right]\right]\right]\right]$

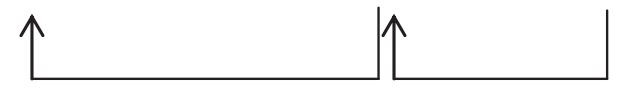

Like DP movements, head movements also respect the MLC-each head adjoins to the closest functional head that c-commands it.

\section{(ii) "DO" extraction}

We have shown in the preceding sections that in its T-function, an IA promotes as the trigger the transported theme/causand of a ditransitive verb. Relevant examples are repeated as follows:

(61) a. os-'o_f-a-eni_ta_mo'o_si_tposx

TR.RL-1SG.ERG_give-TR-IA_OBL_PN_ABS_book

I gave the book to Mo'o.

b. os-'o_poa_haf-a-neni_to_paicx_'o_yungku

TR.RL.-1SG.ERG_CAUS_carry-TR-IA_OBL_PN_ABS_basket

I let Paicx carry the basket. 
There arises a paradox. On the one hand, the triggers tposx 'book' and yungku 'basket' are the arguments semantically selected by the base verbs in $61 \mathrm{a}-\mathrm{b}$ and hence expected to originate as the complements of the base verbs. On the other hand, it has been established above that a transported theme/causand is merged in SpecApplP. How to accommodate this paradox?

Inspired by Newman's idea and the Archaic Chinese faithful manifestation of the idea mentioned in the preceding section, I propose that a T-function IA occurs as a complex predicate. In the complex predicate, a T-function IA head takes a transported theme/ causand as its specifier and a causative $v \mathrm{P}$ as its complement. The causative $v \mathrm{P}$ complement represents either an inherently ditransitive verb such as faeni 'give' or a causativized transitive verb such as pahaf(a)neni 'cause to bring'. As suggested above, the placement of a transported theme/causand in the specifier of an IA is semantically and morphologically motivated-only the theme/patient of a ditransitive verb (i.e., a transported theme/causand) can be conceptualized as an instrument and therefore receives an instrumental marking; an ordinary theme/patient is unable to occur in the specifier of an instrumental applicative and obtain the instrumental marking. In the present analysis, the transported theme/causand in SpecApplP antecedes an empty category which is base-generated as the complement (i.e., DO) of the base verb embedded down in the causative phrase and moved to the edge of the highest $\nu \mathrm{P}$ in the embedded phrase, as schematized as follows ('TT' for 'transported theme'; 'CND' for 'causand'):

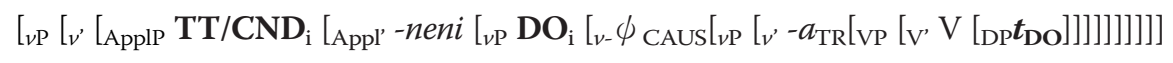

Here, we treat the empty category in the complement of the base verb as a variable rather than a small pro on grounds that (i) it cannot be replaced with an overt pronoun; (ii) it must be coreferential to the antecedent applied object. In this sense, the proposed underlying structure for a T-function IA looks like an object-sharing purposive in English. Compare:

\section{(63) I bought the book $k_{\mathrm{i}}\left[\mathrm{CP} o p_{\mathrm{i}}\right.$ to [vp read $\left.t_{\mathrm{i}}\right]$.}

Meanwhile, it is noted that the two differ in two ways. First, a T-function IA is an applicative, whereas an object-sharing purposive is a transitive construction. Second, they are different in the size of their embedded phrase: it is a $\nu \mathrm{P}$ in an T-function IA, but a $\mathrm{CP}$ in an object-sharing purposive.

Actually, a T-function IA head behaves very much like the preposition $y i$ in Archaic Chinese. Recall that $y i$ is derived from a verb of holding/carrying. In this view, a sentence like 61a 'I gave the book to Mo'o' will literally mean 'I carried the book and let Mo'o to have it' and a sentence like 61b 'I let Paicx to carry the basket' will literally read as 'I held the basket and let Paicx to carry it'. As the highest internal argument, a transported theme/causand merged in SpecApplP has the privilege of advancement. Since the transported theme/causand in SpecApplP is coreferential to an empty pronoun as a DO in the complement of the base verb, it looks as if the DO entertains the privileged advancement. This explains the "DO" extraction in a T-function IA presented 
above. In the context of $61 \mathrm{~b}$, the "DO" extraction turns out to be the applied object extraction:

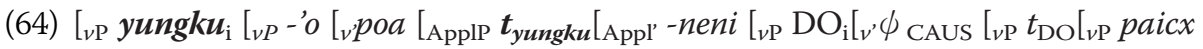
$\left[v^{\prime}-a\left[\mathrm{vP}\left[\mathrm{v}^{\prime}\right.\right.\right.$ haf $\left.\left.\left.\left.\left.\left.\left.\left.\left.\left.\left.\left.\left[\mathrm{DP}_{\mathrm{DO}}\right]\right]\right]\right]\right]\right]\right]\right]\right]\right]\right]\right]\right]$

Meanwhile, the proposed analysis predicts that the extraction of an IO will violate the MLC and is therefore ruled out. This prediction is borne out, as illustrated in 65 . The diagram in 66 demonstrates graphically how the IO extraction in 65b violates the MLC.

(65) a. "os-'o_f-a-eni_ta_tposx_'o_mo'o

TR.RL-1SG.ERG_give-TR-IA_OBL_book_ABS_PN

Intended for I gave Mo'o the book.

b. "OS-'o_poa_haf-a-neni_to_yungku_'o_paicx

TR.RL-1SG.ERG_CAUS_carry-TR-IA_OBL_basket_ABS_PN

Intended for I let Paicx carry the basket.

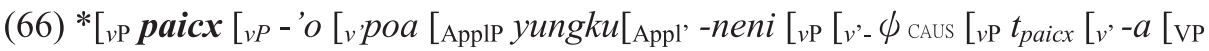

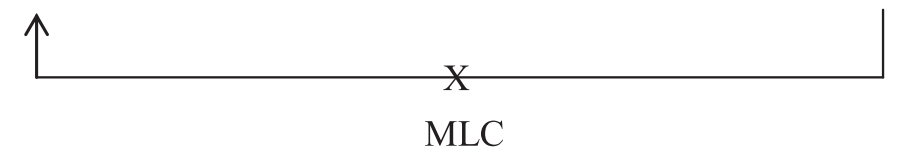

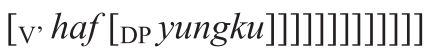

It becomes more evident by now that despite being a high applicative, a T-function IA does not form a phase by itself, hence disallowing a lower object to move across a higher one.

In this analysis, a T-function IA and an I-function IA behave alike with regard to extraction: in both cases, it is the applied object that is advanced as the trigger, regardless of whether the applied object is a(n) beneficiary/instrument or a transported theme/causand.

Note, however, that a T-function IA and its I-function counterpart are not identical in terms of their structural complexity. Compare, for instance, Example 62 with Example 57. In an I-function IA like the one represented in 57, the applicative head takes a simple VP as its complement. Nevertheless, in a T-function IA as schematized in 62, the applicative head takes a complex $\nu \mathrm{P}$ as its complement. The contrast in structural complexity between the complement of a T-function IA and that of an I-function IA is morphologically marked on the verb. Recall that the applicative suffix -(n)eni immediately follows the base verb in I-function IA, as in 55. In contrast, $-(n) e n i$ and the base verb are intervened by a causative and transitive affix in a T-function IA, as in 61 .

A clarification is needed at this point. Given that a causative morpheme precedes the base verb in Tsou, how could we know that a causative $v \mathrm{P}$ is built under the applicative head represented by a suffixal $-(n)$ eni? While the answer to this question has been hinted in section Causatives, it may be helpful to reiterate two of the major reasons here. The first piece of supporting evidence is concerned with the I-T functional division stated in 47. Remember that a causativized transitive verb behaves on a par with an inherently ditransitive verb in the trigger advancement in that an IA which applies to a causativized transitive verb performs a T-function rather than an I-function, as opposed to an IA that applies to a plain 
transitive verb. This has been exemplified in 48a-b, repeated below as $67 \mathrm{a}-\mathrm{b}$. Here, we add another IA with the free-standing causative verb poa for comparison, as in 67c.

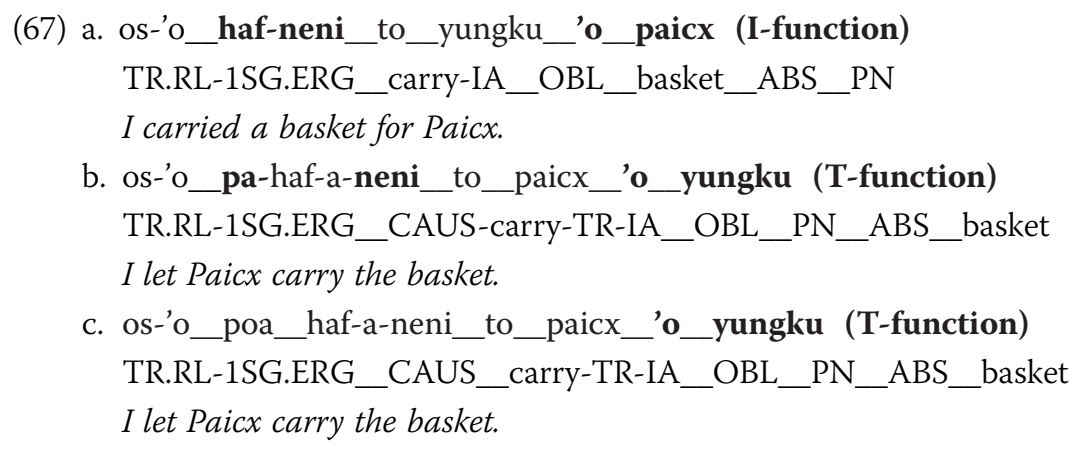

This informs that either the causative prefix $p a$ - or the causative verb poa patterns with the base verb to form a ditransitive predicate prior to the suffixation of the IA suffix -(n)eni. In light of the Mirror Principle (Baker 1985), the order of combination entails that a causative $v \mathrm{P}$ is merged under a T-function IA head.

The second piece of supporting evidence comes from the order of a causative prefix and a T-function IA prefix in other Formosan languages. As in 68-70, a T-function IA prefix consistenly occurs external to a causative prefix in Seediq, Paiwan, and Atayal:

(68) Seediq (Holmer 1999: 427, glosses mine, HYC)

s-p-iimah-mu_pawan_sino_nii.

IA-CAUS-drink-ISG.ERG_PN_wine_this

I invite Pawan to drink this wine.

(69) Paiwan (Chaolin Li, personal communication)

si-pa-veli_ni_camak_a_vavuy_tjay_palang.

IA-CAUS-buy_ERG_PN_ABS_wild.pig_OBL_PN

Camak sold the wild pig to Palang.

(70) Mayrinax Atayal (Chunming Wu, personal communication)

si-pa-nubuag_ni'_watan_'i'_tapas_ku'_qusia'

IA-CAUS-drink_ERG_Watan_OBL_Tapas_ABS_water

Watan caused Tapas to drink the water.

Structurally speaking, this means that a T-function IA head is merged above a causative $v \mathrm{P}$ in Seediq, Paiwan, and Atayal. Given that the IAs in the Seediq/Paiwan/ Atayal examples (68-70) are syntactically parallel to the Tsou examples (67b-c), the conclusion derived from the former group of languages arguably also holds in the latter one.

\section{Towards an explanation of double transitives}

In section Extraction asymmetries, we have pointed out that the previous analyses of IAs fail to account for double transitives/applicatives in Tsou and Bunun. In Tsou, a 
double transitive advances a transported theme/causand as the trigger and consists of a transitive plus an IA. The configuration of a double transitive is subject to two important restrictions: (i) the suffix -(n)eni that represents the IA component must occur external rather than internal to the suffix $-a$ that represents the transitive component; (ii) the IA involved must be in its T-function instead of its I-function.

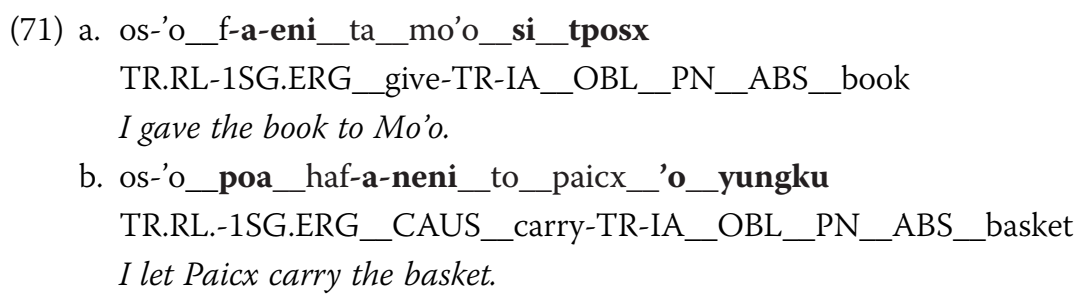

This is nicely accounted for by the present analysis. As schematized in 62, a T-function IA head takes a causative $v \mathrm{P}$ as its complement. It comes as no surprise that an IA suffix -(n)eni must occur external to a causative affix and a transitive suffix $-a$. It is also expected in the present analysis that an IA in a double transitive is in its T-function instead of in its I-function, since only in the T-function, an IA is associated with a ditransitive verb and advances its transported theme/causand, as already stated in 47 and 66. Crucially, the structural placement of a theme/patient in the specifier of an instrumental applicative requires the presence of a ditransitive verb which involves the transfer of the theme/patient semantically. It is generally understood that a semantically complex event of object transportation is morphosyntactically complex. Recall that a ditransitive is either represented as a VP-shell (Larson 1988) or a composite causative $v$ P (Harley 2002).

The order of a T-function IA above a causative and a transitive in a double transitive is semantically/pragmatically well-motivated and syntactically captured in the proposed complex predicate analysis. Analytically, as a verbal element of holding/ carrying, a T-function IA head starts the complex event of object transportation by bringing an object into the scene, followed by a causative event where the object travels from an individual to another. In terms of information structure, this means that the transported object is the topic of the whole event. In an ergative language like Tsou, this translates into the grammatical transitivity of the complex predicate. In terms of topic continuity, the grammatical transitivity will go all the way through the complex predicate. This underlies the morphological makeup of a double transitive, in particular, the transitive marking of the innermost predicate.

\section{Extractions in LAs}

Uniform 10 extraction

Like a typical locative applicative, a LA normally relates a location, goal, or source to the event described by the verb in Tsou. The example below illustrates that an LA introduces a goal to the event of laughing.

(72) i-ta_cocv-i_na_a'o

TR.RL-3SG.ERG_laugh-LA_ABS_1SG

He laughed at me. 
It is observed in 73a-b that an LA relates a goal to the event of sending a book and that of giving money.

(73) a. os-'o_pai'un-i_to_tposx_'o_mo'o

TR.RL-1SG.ERG_send-LA_OBL_book_ABS_PN

I sent Mo'o a book.

b. i-si_fi-i_ta_peisu_si_paicx.

TR.RL-3SG.ERG_give-LA_OBL_money_ABS_PN

He gave Paicx money.

In 74a-b, an LA introduces a location to the event of standing and sitting.

(74) a. i-ta_yac'-i_si_fatu

TR.RL-3SG.ERG_stand-LA_ABS_stone

He stands on the stone.

b. i-si_yusuhng-i_'o_hopo

TR.RL-3SG.ERG_sit-LA_ABS_bed

He sits on the bed.

There is no question that an LA represents an ApplP, with a location or a goal merged in its specifier. Given the non-existence of a low applicative (see section Dispensing with the high-low applicative distinction), the ApplP under consideration should be built above VP but under $v$ P, just like the one represented by an IA. The applied object, labeled as an IO, is advanced from SpecApplP first to the edge of the c-commanding $v \mathrm{P}$ and then to the top of the sentence. Accordingly, the first phase derivation of Example 72b can be given as follows:

(75) $\left[{ }_{\nu \mathrm{P}}\right.$ paicx $\left[{ }_{\nu \mathrm{P}}-s i\left[{ }_{v^{\prime}}-\phi\left[\mathrm{ApplP} t_{\text {paicx }}\left[\mathrm{Appl} \mathrm{P}^{\prime}-i\left[\mathrm{vP}\left[\mathrm{v}^{\prime}\right.\right.\right.\right.\right.\right.$ fi- [DP peisu $\left.\left.\left.\left.\left.\left.\left.]\right]\right]\right]\right]\right]\right]\right]$

It has been pointed out in section Extraction asymmetries that unlike an IA, an LA prohibits the extraction of a DO. The following examples confirm the observation. Compare 76 with 73 :

(76) a. "os-'o_pai'un-i_to_mo'o_'o_tposx

TR.RL-1SG.ERG_send-LA_OBL_PN_ABS_book

b. "i-si_fi-i_ta_paicx_'o_peisu.

TR.RL-3SG.ERG_give-LA_OBL_PN_ABS_money

This is accounted for nicely in the present analysis. With an IO merged high in SpecApplP, the extraction of the lower DO will yield an MLC violation, as represented below for the example in 76b:

(77) $*\left[{ }_{\nu \mathrm{P}}\right.$ peisu $\left[{ }_{\nu \mathrm{P}}-\mathrm{si}\left[\mathrm{v}^{\prime}-\phi\left[\mathrm{ApplP}\right.\right.\right.$ paicx $\left.\left.\left.\left[\mathrm{Appl},-i\left[\mathrm{vP}\left[\mathrm{v}, f i-\left[\mathrm{DP} t_{\text {peisu }}\right]\right]\right]\right]\right]\right]\right]$

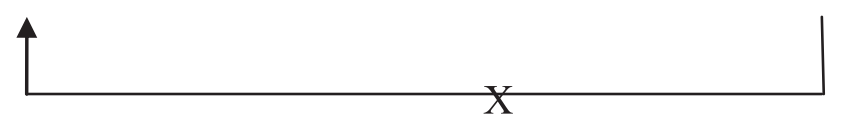


For verbs of perception and cognition, an LA appears to be able to extract a DO. Consider:

(78) a. i-ta_ait-i_ne hucma_si_mo'o

TR.RL-3SG.ERG_look-LA_yesterday_ABS_PN

He saw Mo'o yesterday.

b. os-'o_cohiv-i_co_to'hxngx-taini

TR.RL-1SG.ERG_aware-LA_ABS_thought-3SG.POSS

I knew his thought.

At first glance, the triggers mo'o and to'hxngx-taini seem to be extracted from the complement of the base verbs ait and cohiv, respectively, given that they are treated as the theme of the respective perception verb and cognition verb under the standard theory. However, a closer inspection indicates that this is not the case. In Tsou, the alleged theme of a perception/cognition verb occurs only in two positions, namely, either in an oblique position in an intransitive construction or in a topic position as the trigger in an LA. In the first position, it must be introduced by an oblique case marker, whereas in the second position, it must be led by an absolutive case marker and an LA suffix $-i$. The second scenario has been illustrated in 78 ; the following example exemplifies the first scenario.

(79) a. mi-ta_baito_to_mo'o

INTR.RL-3SG.ABS_look(INTR)_OBL_PN

He is looking at Paicx.

b. mi-'o_bochio_to_ongko-si

INTR.RL-1SG.ABS_aware(INTR)_OBL_name-3SG.POSS

I am aware of his name.

In Tsou, perception and cognition verbs are not associated with a plain transitive suffix - $a$, hence the ill-formedness of the transitive forms "aita and "cohiva. This restriction, together with the licensing condition on the alleged theme, suggests that perception verbs and cognition verbs start out as a one-place verb. The perception verb baito in 79a translates literally as 'look' and the cognition verb bochio in 79b as 'be aware'; the oblique case marker to functions on a par with the English prepositions at or of in introducing a corresponding theme. The LA examples in 78a-b represent the other way of introducing the alleged themes in Tsou, that is, introducing them by the LA head $-i$. In light of Baker (1988), $-i$ can be regarded as a locative preposition that is incorporated into the verb. Transformationally, the $i$-incoporation turns the intransitive verbs baito and bochio in 79a-b into the applied verbs aiti and cohivi in 78a-b, in much the same way that the English prepositions at and of are incorporated into the intransitive verbs look and be-aware and give rise to the hypothesized applied verbs look-at (actually realized as a transitive verb see) and be-aware-of (actually realized as a transitive verb know), respectively.

In this view, the LAs in 78a-b are typical locative applicatives and the triggers mo'o and to'hxngx-taini are originatd from SpecApplP as a goal instead of from the complement of the base verbs as a theme. In other words, they involve the extraction of an IO rather than a DO. The first derivation of Example 78a can be diagramed as follows:

(80) $\left[{ }_{\nu \mathrm{P}} m o^{\prime} O\left[{ }_{\nu \mathrm{P}}-t a\left[v^{\prime}-\phi\left[\mathrm{ApplP} t_{m o^{\prime} o}\left[\mathrm{Appl}{ }^{-}-i\left[\mathrm{VP}\left[\mathrm{V}^{\prime}\right.\right.\right.\right.\right.\right.\right.$ ait-]]]]]]] 
It is thus concluded that an LA consistently extracts an IO in Tsou and that a Tsou LA prohibits the extraction of a DO. This is reminiscent of McGinnis's non-phasal analysis of low applicatives in Kinyarwanda (see section McGinnis's phase account of applicatives). It is also noteworthy that this conclusion holds true of double applicatives, where an LA is placed under an IA. We shall return to this issue in a minute.

\section{Towards an explanation of double applicatives}

In Tsou, a double applicative is comprised of two applicative components, with an LA occurring internal to an IA in a clause. Tsou double applicatives can be classified into two types with regard to the presence of a causative: the first type contains a causative, whereas the second type lacks a causative. It should be noted that in both classes, it is an IO rather than a DO that is advanced as the trigger and that in both classes, the IA component is in its I-function rather than T-function. Let's consider the causative type first.

\section{(i) Causative double applicatives}

A causative double applicative is made up of a causative, an LA, and an IA. The order of the three components is that an IA occurs external to an LA and a causative ${ }^{k}$. For instance:

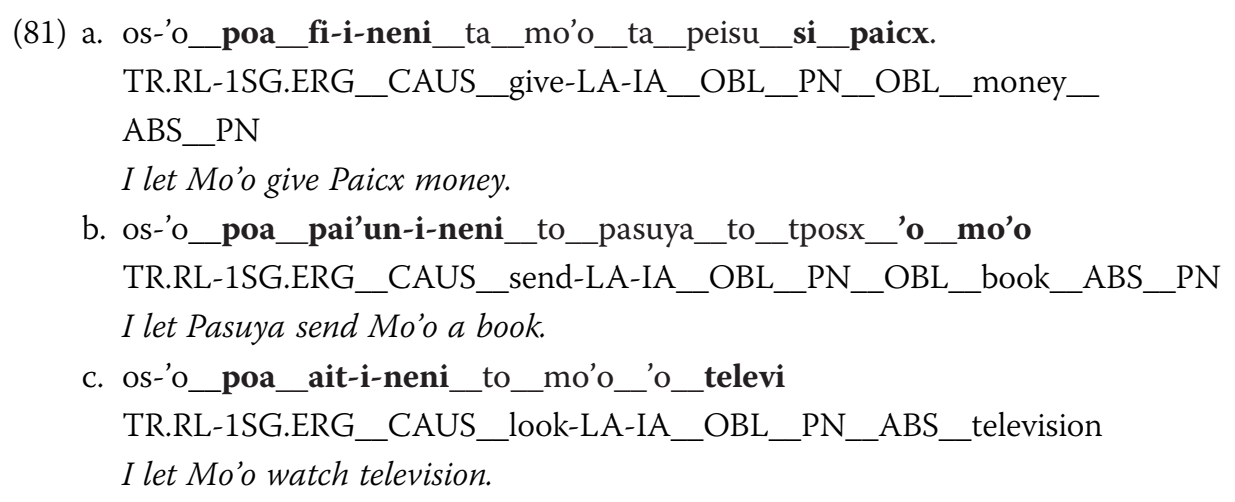

As noted in Huang and Huang (2007), the trigger of the double applicative in question is the same as that of its LA component: like 78a and 76b, the trigger in $81 \mathrm{a}-\mathrm{c}$ is the goal of the base verb. Given this, what is the function of the IA component? Note that the IA cannot be left out, as indicated in the ungrammaticality of the following sentences.

(82) a. "os-'o_poa_fi-i_ta_mo'o_ta_peisu_si_paicx.

$$
\begin{aligned}
& \text { TR.RL-1SG.ERG_CAUS_give-LA_OBL_PN_OBL_money_ABS_PN } \\
& \text { b. "OS-'O_poa_pai'un-i_to_pasuya_to_tposx_'o_mo'o } \\
& \text { TR.RL-1SG.ERG_CAUS_send-LA_OBL_PN_OBL_book_ABS_PN } \\
& \text { c. "OS-'O_poa_ait-i_to_mo'o_'o_televi } \\
& \text { TR.RL-1SG.ERG_CAUS_look-LA_OBL_PN_ABS_television }
\end{aligned}
$$

This suggests that the IA plays an important role in the licensing of the trigger. Taking this into consideration, I propose that the IA component merges in its specifier a 
beneficiary which antecedes the goal base-generated in the specifier of the LA component and that as the highest internal argument, the beneficiary is advanced as the trigger. In this analysis, the IO extraction in $81 \mathrm{~b}$ can be represented as follows:

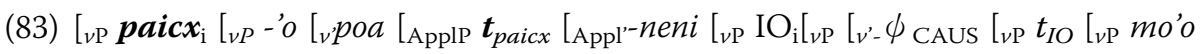

$\left[v^{\prime}-\phi_{\mathrm{TR}}\left[\mathrm{ApplP} \boldsymbol{t}_{\boldsymbol{I}}\right.\right.$ [Appl' $-i\left[\mathrm{VP}\left[\mathrm{V}^{\prime}\right.\right.$ fi- [DP peisu]]]]]]]]]]]]]

In addition, the IO (i.e., the goal) is moved to the edge of the highest $\nu \mathrm{P}$ in the complement, a position closest to its antecedent. The movement is akin to the operator movement in a goal-sharing purposive in English, as indicated below.

(84) I went to the supermarket ${ }_{\mathrm{i}}\left[\mathrm{CP}\right.$ op $p_{\mathrm{i}}$ to [VP buy fruits $\left.t_{\mathrm{i}}\right]$.

This analysis also predicts that the MLC will rule out a DO extraction in 81 . The prediction is borne out, as shown in 85 .

(85) a. "os-'o_poa_fi-i-neni_ta_mo'o_ta_paicx_si_peisu TR.RL-1SG.ERG_CAUS_give-LA-IA_OBL_PN_OBL_PN_ABS_money

b. " os-'o_poa_pai'un-i-neni_to_pasuya_to_mo'o_'o_tposx TR.RL-1SG.ERG_CAUS_send-LA-IA_OBL_PN_OBL_PN_ABS_book

c. " os-'o_poa_ait-i-neni_to_telivi_'o_mo'o TR.RL-1SG.ERG_CAUS_look-LA-IA_OBL_television_ABS_PN

A similar asymmetry of extraction is also found in non-causative double applicatives, as will be discussed in the next section.

\section{(ii) Noncausative double applicatives}

A non-causative double applicative is comprised of an IA occurring external to an LA. It is not as productive as a causative double applicative. However, it behaves like a causative double applicative in its syntactic operation. As shown in 86 , a non-causative double applicative also advances an $\mathrm{IO}$ as the trigger.

(86) te-ko-n'a_phin-i-neni_to_simeo_(na)_a'o

IRR-2SG.ERG-DT_buy-LA-IA_OBL_pork_ABS_1SG.ABS

Buy me some pork!

In contrast, it does not allow the extraction of a DO:

(87) "te-ko-n'a_phin-i-neni_a'o_'o_simeo

IRR-2SG.ERG-DT_buy-LA-IA_1SG.OBL_ABS_pork

It is evident that a non-causative double applicative is syntactically not distinct from its causative counterpart. Given the parallelism, the proposed complex predicate above can apply here as well. This will assign Example 86 the following structure and derivations: the beneficiary $a^{\prime} o$ is merged in the specifier of the IA, controlling the reference 
of the phonologically null goal in the specifier of an LA, and advanced to the edge of the highest $v \mathrm{P}$.

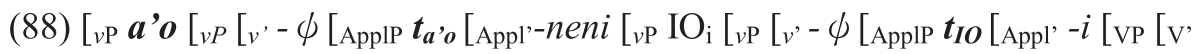

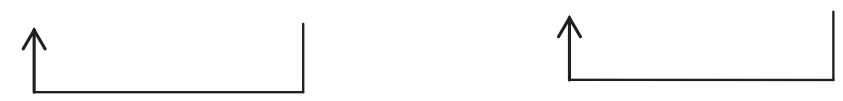

phin- [DP simeo]]]]]]]]]]]]]

In other words, 86 has a literal meaning of 'to my benefit, please buy me some pork'.

In the mean time, it goes without saying that the extraction of the lower object simeo 'pork' will be ruled out by the MLC.

This aligns a double applicative with a double transitive-like a double transitive, a double applicative occurs as a complex predicate. In the complex predicate, an IA head functions as a matrix predicate and introduces an applied object for the secondary predicate to be predicated of. Nonetheless, a double applicative differs from a double transitive in that (i) it sets an IA in its I-function rather than in its T-function; (ii) it advances as the trigger a genuine IO instead of an IO in the disguise of a DO.

The proposed complex predicate analysis of double applicatives is by no means arbitrary. Remember that a causative double applicative is morphologically complex, consisting of two distinct applicative affixes and a causative morpheme. Given that each of the named morphemes is typically associated with a $\nu \mathrm{P}$ in syntax, the complex morphology lends direct support to the proposed complex predicate analysis. Besides, the identification of a goal with a beneficiary is semantically motivated. The goal of an action can be its beneficiary. This is particularly the case when the goal is human and the action involves a transfer of possession. The goal-beneficiary interrelation is cross-linguistically attested. For instance, in English, a goal in a double object construction can occur as a beneficiary (witness the occurrence of the benefactive preposition for) in another synonymous construction, as in 89 .

(89) a. John bought Mary a gift.

b. John bought a gift for Mary.

In Mandarin Chinese, both a goal and beneficiary can be marked by the same preposition 給 gei 'to', which evolves from a verb of giving. Interestingly, for the prepositional gei, there is a strong correlation between its distribution and function: it functions as a benefactive marker (akin to the English benefeactive phrase to the benefit) preverbally but as a dative marker (akin to the English dative preposition to) postverbally. Compare:

(90) Mandarin Chinese

a. 我寫信給他

wo_xie_xin_zei_ta

I_write_letter_to_him

I wrote a letter to him.

b. 我給他寫信

wo_gei_ta_xie_xin

I_for_him_write_letter

I wrote a letter for him. 
Given that a preverbal element is projected in a higher position than its postverbal counterpart in Mandarin Chinese, the asymmetrical distribution of gei in 90 informs clearly that the preverbal benefactive gei should be placed in a higher position than its postverbal dative counterpart. In other words, a benefactive phrase dominates a dative one structurally, definitely not the other way around. This accords with the hierarchical structure represented in 88 , where a benefactive applicative headed by $-(n)$ eni is merged above a locative applicative headed by $-i$. It is reasonable to align -(n)eni with the preverbal benefactive gei and $-i$ with the postverbal dative gei, following Baker's observation that an applicative affix is an incorporated version of a corresponding preposition.

\section{DO-topicalization and the I-T functioal split}

In the preceding section, it is observed that a double applicative sets an IA in its Ifunction rather than its T-function. This poses a problem on the generalization in 47 . The verb to which an IA applies can be a ditransitive in a double applicative, as in 81a. The generalization in 47 predicts that the IA should be in its T-function, contrary to the fact. Obviously, the generalization needs to be revised.

It is noteworthy that a T-function IA applies to a ditransitive with its DO topicalized in the complement. The embedded DO toplicalization is encoded by the transitive suffix $-a$ occurring right after the base verb, as already shown in 71 , repeated below as 91a. The embedded topicalization is obligatory, as illustrated in the ungrammatical 91b, where the theme remains in situ and the verb receives an intransitive marking.

(91) a. os-'o_f-a-eni_ta_mo'o_si_tposx

TR.RL-1SG.ERG_give-TR-IA_OBL_PN_ABS_book

I gave the book to Mo'o.

b. "os-'o_mo-fi-eni_ta_mo'o_ta_tposx

TR.RL-1SG.ERG_INTR-give-IA_OBL_PN_OBL_book

In contrast, the embedded DO topicalization is not attested in a double applicative; instead, what undergoes the embedded topicalization is an IO, as already exemplified in 81a, repeated below as 92 (witness the occurrence of an LA suffix $-i$ immediately after the base verb).

(92) os-'o_poa_fi-i-neni_ta_mo'o_ta_peisu_si_paicx.

TR.RL-1SG.ERG_CAUS_give-LA-IA_OBL_PN_OBL_money_ABS_PN

I let Mo'o give Paicx money.

It becomes clear by now that an embedded topicalization also plays a role in the I-T functional division. More precisely, a T-function is attested only when the base ditransitive topicalizes its DO. In view of this additional restriction, I suggest that 47 be reformulated as 93 .

(93) I-T functional division (Revised)

An IA advances a transported theme/causand as the trigger iff it applies to a ditransitive verb that topicalizes its DO (T-function); otherwise, it advances a(n) beneficiary/instrument as the trgger (I-function). 
A generalization following from 93 is that an I-function is the default function of an IA, whereas its T-function is highly restricted and hence typologically uncommon.

\section{Further up}

\section{Moving further to SpecCP}

In the preceding sections, we have established that an applied object moves to the edge of the highest $v \mathrm{P}$. But the moved object does not stop there. In this section, I argue that the moved object shifts further to SpecCP.

Richards (2000) and Pearson (2005) argue convincingly that the trigger in Tagalog and Malagasy behaves like a topic rather than a subject with respect to a number of important syntactic/semantic properties, including specificity, imperative deletion, topic drop, and semantic reconstruction. Along this line of thought, M. Chang (2004) identifies the trigger in Tsou as an A'-element rather than an A-element. In what follows, I provide three additional pieces of evidence in support of their analysis.

First, as in Tagalog and Malagasy, the trigger is normally definite in Tsou. As in 94a, the object tposx 'book' is indefinite in its base position. Nonetheless, once advanced as the trigger, it turns out to be definite, as in $94 \mathrm{~b}$.

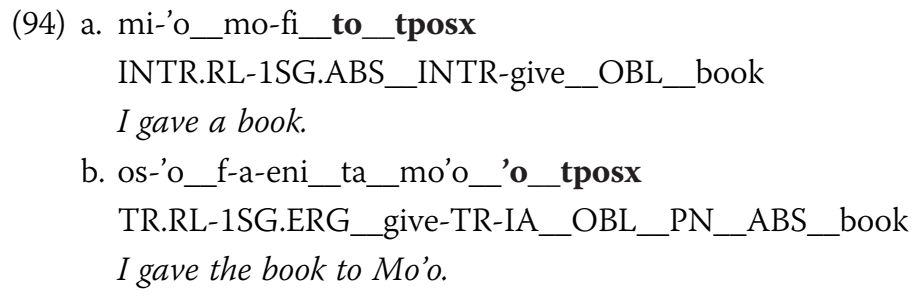

Given that a definiteness restriction is required for a topic, not for a subject, this will identify the trigger in question as a grammatical topic.

Second, like its counterpart in Tagalog and Malagasy, a reflexive can move past its binder and surface as the trigger in Tsou, as in 95 .

(95) os-'o_poa_p'ecihi-neni_ta_mo' $\mathbf{o}_{\mathbf{i}} \_$ne hucma_'o_iachi-si $\mathbf{i}_{\mathbf{i}} \_$ongko

TR.RL-1SG.ERG_CAUS_step(TR)-IA_OBL_PN_yesterday_ABS_self-

3SG_shadow

I let Mo'o step on his own shadow yesterday.

To satisfy the Binding Principle A, the reflexive iachisi 'himself' must be reconstructed back to its base position for a proper binding/interpretation. This aligns the trigger with an A'-element (Example 96) instead of an A-element (Example 97). Compare:

(96) a. Which pictures of himself $f_{\mathbf{i}}$ did Mary say that every boy ${ }_{i}$ should burn $t_{\text {which }}$ ?

b. Herself, we know she admires $t_{\text {herself. }}$ (Büring 2004: 247)

(97) a. Every boy seems to himself $t_{\text {every boy }}$ to be a genius.

b. "Himself seems to every boy $t_{\text {himself }}$ be a genius. (based on Büring 2004:244) 
Last, but not the least, the advancement as the trigger blocks $\mathrm{A}^{\prime}$-movements in Tsou. Like other Philippine-type languages, A'-movement displays the absolutive restriction in Tsou. As in 98a-c, only the absolutive DP can undergo an operator movement to the specifier of a $\mathrm{CP}$ which modifies a null head noun within a complex DP that is predicated of by a wh-phrase in the sentence-initial position. Compare:

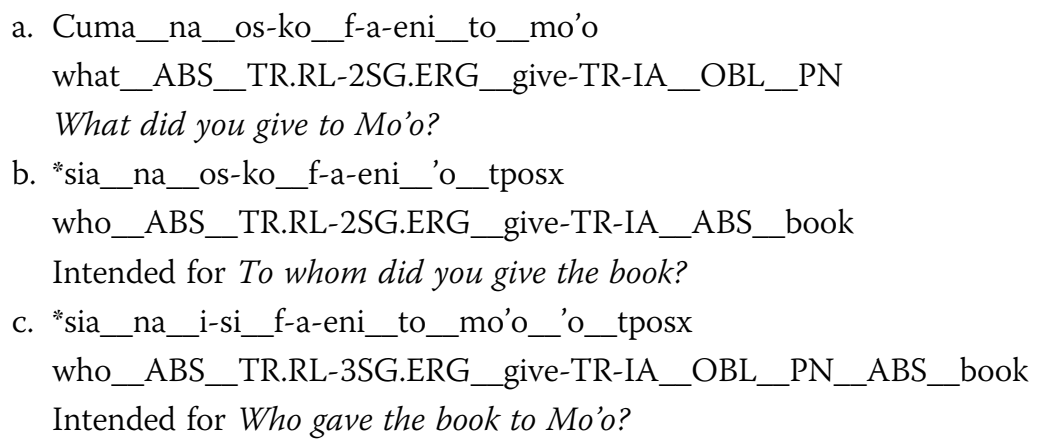

This falls out naturally if the advancement as the trigger is also an instance of $\mathrm{A}^{\prime}$-movement. Once the movement of a trigger deletes the uninterpretable EF on the Probe $\mathrm{C}^{0}$, the Probe will be inactive and hence unable to attract any other $\mathrm{A}^{\prime}$-element within its c-commanding domain. Also, since the shifted object is the closest internal argument to the Probe $C^{0}$, the movement of any other argument will violate the MLC. This locality effect cannot be accounted for nicely if the advancement as the trigger is an A-movement-if the trigger was an A-element, it would not prevent an A'-element from extraction at all. In English, for example, an A'-movement can take place after an A-movement without any intervention effect, as in $99 a-b^{1}$.

(99) a. Who do you think the book was written by?

b. Who do you think this present was given to Mary by?

For the above-mentioned reasons, I assume that the shifted object moves one step further into SpecCP rather than SpecTP. The CP is presumably headed by any of the finite auxiliary listed in Table 1 in section A grammatical sketch of Tsou (abbreviated as $\mathrm{C}_{\text {FIN }}$ ). In the case of a double transitive in 61a, the head of the $\mathrm{C}_{\mathrm{FIN}} \mathrm{P}$ is a transitive mood auxiliary $i$-. The $\mathrm{C}_{\mathrm{FIN}} i$ - has an EF, which attracts the shifted object f'ue 'sweet potato' to its outer specifier, as shown below.

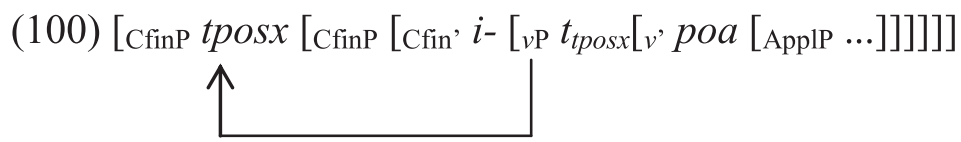

It is remarkable that the $\mathrm{C}_{\mathrm{FIN}} i$ - registers a movement-triggering feature $\mathrm{EF}$ in terms of its overt marking of grammatical transitivity. Recall that in its realis category, the mood auxiliary additionally encodes grammatical transitivity, as already presented in Table 1 in section A grammatical sketch of Tsou. 
Finally, there comes a remnant movement that fronts the remaining $\mathrm{C}_{\mathrm{FIN}} \mathrm{P}$ to the left of the trigger tpos $x$, yielding the surface predicate-initial and trigger-final word order in 61a. Consider:

\section{(101) $\left[{ }_{\mathrm{CP}} \mathrm{C}_{\mathrm{FIN}} \mathrm{P}\left[\mathrm{CfinP} \operatorname{tposx}\left[t_{\mathrm{CfinP}}\right]\right]\right]$}

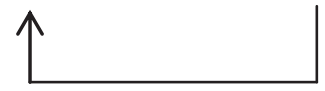

The A'-movement analysis accords with Richards (2000), M. Chang (2004), and Pearson (2005). In addition to the definiteness requirement and the semantic reconstruction effect, it also accounts for the locality effect observed in the trigger extraction and the operator movement in headless relative clauses. Unlike an A-movement, the final landing of a shifted object is driven by an EF on the Probe $\mathrm{C}_{\mathrm{FIN}}$ rather than by an EPP feature on $\mathrm{T}$; its landing site is at SpecCP instead of SpecTP.

The same derivations apply to a double applicative as well. There is no need to duplicate them here.

\section{Concluding remarks}

We have established that applicatives are divided into two types in Tsou: an instrumental/benefactive applicative (IA) and a locative applicative (LA). An IA and an LA differ from each other in three important respects:

(102) IA vs. LA

a. An LA advances as the trigger a spacial argument such as a location, goal, or a source, whereas an IA advances as the trigger either a(n) instrument/ beneficiary or a transported theme/causand;

b. An IA can merge above an LA, not the other way around; the stacking of an IA over an LA yields a double applicative;

c. An IA, but not an LA, can merge above a transitive; the stacking of an IA over a transitive gives rise to a double transitive;

d. An IA, but not an LA, can form a complex predicate.

Still, an IA and an LA share two core properties:

(103) IA and LA

a. Both an IA and an LA are merged above VP but under $v$ P;

b. Both an IA and an LA advances as the trigger an IO rather than a DO.

Both a double transitive and a double applicative occur as a complex predicate, with the applicative head serving as a matrix predicate and introducing an applied object to feed the secondary predicate. Of particular interest is that in a double transitive, the applicative head builds in its specifier a theme/patient that antecedes a DO in the secondary predicate. This makes an IO extraction look like a DO extraction. As a matter of fact, the trigger extraction in an applicative consistently starts from SpecApplP in Tsou. 
An IA performs two distinct functions, namely, an I-function and a T-function. An Ifunction is the typical function of an IA. In contrast, its T-function counterpart is very restricted: it applies only to a ditransitive verb that topicalizes its DO.

These findings have far-reaching typological and theoretical implications, as explored in the following subsections.

\section{Typological implications \\ Double applicatives}

Double applicatives are rare across languages. Only a few languages have been reported to exhibit double applicatives so far (Samkoe 1994). These include Huastec, Kinyarwanda, Sierra Popoluca, Lillooet, Shuswap, and Thompson. Along with Shi, Chaokai and Atul Manqoqo (2013), this paper adds Tsou and Bunun to the impoverished list. However, it should be noted that Tsou and Bunun differ from double applicative languages such as Kinyarwanda in that Tsou and Bunun are asymmetrical object languages which extract only the applied object.

\section{Syntactic ergativity}

It is evident that both an IA and an LA are transitive constructions. However, what is advanced as the trigger in either type is an internal argument, but not an external argument (agent or causer). This is characteristic of ergative languages and an essential part of Tsou grammar.

\section{Asymmetricality}

In both types of Tsou applicatives, only one of the objects is eligible for extraction. This aligns Tsou with the Chichewa-type asymmetrical object languages instead of the Kichaga-type symmetrical object languages (Baker 1988, Bresnan and Moshi 1990, Alsina and Mchombo 1993, Marantz 1993, Donohue 1996, McGinnis 2001, among others).

\section{Morphologically applicative language}

While the grouping of a transported theme/causand as an instrument and that of a goal as a beneficiary are encoded by prepositions in English and Chinese, they are carried out by applicative morphology in Tsou as well as other Formosan languages. In this sense, Tsou can be identified as a morphologically applicative language, as opposed to English and Chinese, which are not morphologically applicative languages.

\section{Theoretical Implications}

\section{Instrumental applicative as complex predicate}

If the proposed analysis is correct, an instrumental applicative can surface as a complex predicate. This opens up a new device of forming a complex predicate. It is also noteworthy that there is an applicative asymmetry-unlike an instrumental applicative, a locative applicative does not form a complex predicate; an instrumental applicative can generally entertain a larger structure than a locative applicative.

\section{Dispensing with low applicative and expletive applicative}

It has been shown that applicatives are consistently merged above VP in Tsou and that low applicatives are not attested in the language. This is in accordance with Larson 
(2010), Paul and Whitman (2010), Chang (2010), and Georgala (2012). This poses a serious challenge for the widely held high-low applicative dichotomy advocated by Pylkkänen (2002, 2008). Likewise, the paper dispenses with the notion of expletive applicative proposed by Paul and Whitman (2010) and Georgala (2012). The proposed complex predicate analysis treats the IA component of a double transitive/applicative which looks like an expletive applicative as representing the matrix predicate of a complex predicate and its applied object as anteceding a(n) DO or IO in the secondary predicate on the basis of complex morphological markings and well-motivated conceptualization of a transported theme/causand as an instrument and a goal as a beneficiary.

\section{Applicative cartography}

In spite of not being a high applicative, a locative applicative is invariably placed under $\mathrm{a}(\mathrm{n})$ benefactive/instrumental applicative in Tsou. Moreover, while a(n) benefactive/ instrumental applicative can merge above a transitive, its locative counterpart cannot do so in the language. Setting aside the problem over low applicative and the issue over phasehood, this is consistent with Tsai (2012) cartography of Chinese applicatives and McGinnis's $(2001,2008)$ structural characterization of Bantu applicatives.

\section{Phasehood and extraction}

To account for applicative asymmetries, McGinnis $(2001,2008)$ relates a high-low applicative dichotomy to a phasal distinction. In her phase-based account, a high applicative in symmetrical languages occurs as a phase and thus renders the leapfrogging of a DO over a higher IO, whereas a low applicative does not constitute a phase and hence disallows the extraction of a DO. However, our findings suggest that a high applicative consistently does not form a phase by itself in Tsou and that the leapfrogging of a DO over an IO is not attested in the language. The phasehood of an applicative is made irrelevant here. Nonetheless, this does not mean that the phasehood of a syntactic projection plays no role in the extraction of its argument. Actually, a transitive $v \mathrm{P}$ constitutes a phase and indeed licenses the crossover of an internal argument over an external argument in the language.

\section{Motivating EF}

Adopting the Minimalist Program, we have relied heavily on an EF or an EPP feature in driving the advancements of an object as the trigger. In particular, we have assumed that every transitive phase head bears an EF in Tsou. This departs from Chomsky's (2000, 2001) original proposal that a transitive phase head may or may not have an EF. In view of the discrepancy, one may argue that the assignment of an EF/EPP feature is arbitrary. In this subsection, I defend the EF/EPP-driven movement analysis and elaborate on its motivations.

Consider the above-mentioned discrepancy first. In speaking of the optionality of an EF, Chomsky is dealing with an accusative language like English. For accusative languages, the EF optionality is empirically motivated. Not every accusative language displays object shift. Icelandic does, but English does not. Even in Icelandic, not every transitive phase head triggers object shift (Vikner 2006).

The story is different in ergative languages. In an ergative language, object shift is obligatory (Aldridge 2004, 2005, 2008a, b). The obligatory property of object shift is attested in Tsou transitive constructions, as extensively discussed in the preceding 
sections. This motivates the assignment of an EF to every transitive phase head in Tsou. In this view, the EF-driven movement analysis captures (if not accounts for) the typological division between Tsou and English/Icelandic.

The EF-driven movement analysis also proves useful in tackling language-internal variation. As presented in section A grammatical sketch of Tsou, grammatical transitivity is morphologically marked on a lexical verb as well as on the preverbal mood auxiliary in Tsou. The EF-driven movement analysis would predict that the transitive set of the mood auxiliary embeds a transitive phase head that bears an EF and requires object shift but its intransitive counterpart does not impose such a requirement. This prediction is borne out correctly. For instance, 104a is intransitive and hence object shift does not take place; by contrast, 104b is transitive and hence object shift is required.

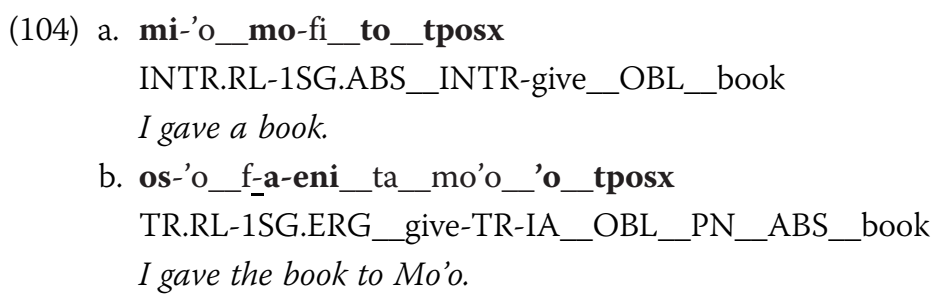

Most importantly, the transitive-intransitive distinction and the occurrence/ nonoccurrence of object shift are overtly marked on a lexical verb and the mood auxiliary in Tsou, i.e. $i$-/faeni vs. mi-/mofi. Abstracting away from the superficial morphological differences, the contrast will be accounted for in a principled manner if we assume that the morpheme $i$-represents an EF, as opposed to the morpheme $m$-, which indicates the absence of an EF.

\section{Strict locality}

The various extractions discussed above all respect a strict locality condition-only the highest internal argument is eligible for the advancement as the trigger. This accords with Rackowski and Richards's (2005) findings in Tagalog. What looks like a longdistance movement turns out to be a local movement. On the other hand, this is at odds with Huang and Huang's (2007) claim that the "voice" operation is lexically determined in Tsou.

\section{Case agreement?}

As surveyed in sections The grammatical agreement approach-The Case agreement approach, the Austronesian "focus/voice" system is analyzed as an agreement between a functional head and the trigger in its original position/Case in the grammatical agreement approach. For Rackowski and Richards (2005), the grammatical agreement yields a four-way distinction of Case agreement markers on the verb, viz., nominative vs. accusative vs. dative vs. oblique. At first glance, the Case agreement seems to be compatible with the proposed complex predicate analysis of the double transitives/applicatives in Tsou, given that a major and a secondary predicate each encode a Case agreement feature in its domain. However, a closer inspection of the facts indicates that this is not the case. Recall that in addition to the lexical verb, the mood auxiliary also exhibits a "focus/voice" distinction in Tsou. Most importantly, the auxiliary "focus/voice" 
distinction is invariably dichotomous, as opposed to the four-way "focus/voice" distinction on the lexical verb. In H. Chang (2009), I have observed that adverbial verbs merged above $\nu \mathrm{P}$ also make a two-way "focus/voice" contrast on a par with the mood auxiliary in Tsou:

(105) 2-way vs. 4-way distinction (Based on H. Chang 2009: 458)

a. mo_asonx_mo-si_ta_pangka_to_emi_o_omo.

INTR.RL_possibly(INTR)_INTR-put_OBL_table_OBL_wine_

ABS_father

Father possibly put wine on the table.

b. i-si_ason-a_si-a_to_amo_ta_pangka_o_o_emi.

TR.RL-3SG.ERG_possibly-TR_put-

TR_ERG_father_OBL_table_ABS_wine

Father possibly put the wine on the table.

c. i-si_ason-a_si-i_ta_amo_ta_emi_o_o_pangka.

TR.RL-3SG.ERG_possibly-TR_put-

LA_ERG_father_OBL_wine_ABS_table

Father possibly put the wine on the table.

d. i-si_ason-a_si-eni_ta_amo_ta_emi_na_a'o

TR.RL-3SG.ERG_possibly-TR_put-

IA_ERG_father_OBL_wine_ABS_1SG.ABS

Father possibly put the wine for me.

The disparity in "focus/voice" marking between the lexical verb and the mood auxiliary/ adverbial verb comes as a surprise to the grammatical agreemegnt approach, since they expect that the "focus/voice" operation should go all the way through the clausal functional heads in a four-way distinction. This is, however, predicted by the present analsysis.

As extensively discussed above, we treat as a system of grammatical transitivity the so-called Austronesian "focus/voice" system. In the prosed framework, a transitive $v$ agrees with and values the highest internal argument within its c-commanding domain in its structural Case feature but an intransitive $\mathrm{C}_{\mathrm{FIN}}{ }^{0}$ the sole argument within its c-commanding domain in its structural Case feature. In both cases, the structurally Case-valued argument is attracted by a local phase head $\left(v / \mathrm{C}_{\mathrm{FIN}}{ }^{0}\right)$, ending up in the edge of $\mathrm{C}_{\mathrm{FIN}} \mathrm{P}$ as the trigger, and occurs invariantly in the absolutive case, owing to the ergative alignment of a transitive $\mathrm{O}$ with an intransitive $\mathrm{S}$ in the language. This nicely accounts for the two-way transitivity distinction on the higher functional heads merged above $v$ as well as the sole structural case-marking in a Tsou sentence. In the meantime, the applicative head Appl under the little $v$ serves to introduce an applied argument to the event described by the verb and thus adds another two dimensions, i.e., IA and LA, to the transitive-intransitive division on the lexical layer.

\section{Endnotes}

${ }^{a} \mathrm{~A}$ more detailed discussion of this can be found in section Research questions.

${ }^{b}$ This paper follows The Leipzig's Glossing Rules, with the following amendments: $\mathrm{Appl} H=$ high applicative, $\mathrm{BA}=$ benefactive applicative, $\mathrm{COS}=$ change of 
state, $\mathrm{DT}=$ downtoner, $\mathrm{EMP}=$ emphatic marker, $\mathrm{EVI}=$ evidential, $\mathrm{NMLZ}=$ nominalizer, $\mathrm{NPST}=$ nonpast, $\mathrm{PLN}=$ place name, $\mathrm{RL}=$ realis, and $\mathrm{SUB}=$ subordinator.

${ }^{\mathrm{C}}$ In spite of their identical formal markings, ergative and oblique DPs behave quite differently in their syntactic behavior. Interested readers are referred to $\mathrm{H}$. Chang (2011c) for a detailed discussion of this issue.

${ }^{\mathrm{d}}$ I differ from Zeitoun (2005: 279) in treating nte as a counterfactual rather than hypothetical marker as well as in taking what she calls voice-marking as marking of grammatical transitivity.

${ }^{\mathrm{e}}$ For the time being, I have no good answer to the question why a few unergative verbs such as those in 6 do not pattern with an LA. Note, however, that it is not the case that all unergative verbs are incompatible with an LA. We shall return to this in section Uniform IO extraction.

${ }^{\mathrm{f}}$ The intransitive counterparts of $6 \mathrm{a}-\mathrm{b}$ are indicated as follows, where the locations surface as obliques:

(i) a. mi-ta_yac'x_ta_fatu

INTR.RL-3SG.ABS_stand(INTR)_OBL_stone

He stands on a stone.

b. mi-ta_yusuhngu_ta_hopo

INTR.RL-3SG.ABS_sit(INTR)_OBL_bed

He sits on a bed.

${ }^{g}$ See Legate (2008) and Richards (2010) for a dissenting view.

${ }^{\mathrm{h}}$ This refers to an IA that applies to a ditransitive/causative verb. An IA can extract the IO if applied to a transitive verb. We will return to this in section Extraction uniformly from the specifier of an IA.

${ }^{i}$ As discussed in Shi, Chaokai and Atul Manqoqo (2013), the compound affix 'is-...-an that attaches only to a dyadic verb and consistently introduces an additional recipient appears to perform the same function as a locative applicative.

'See Paul and Whitman (2010) and Georgala (2012) for a detailed discussion of the thematic-expletive applicative distinction.

${ }^{\mathrm{k}}$ Causative double applicatives are observed with $p o a$, not $p a-$, though poa and $p a$ behave alike syntactically. This may be due to the fact that $p a$ - is not as productive as poa, as noted in section Causatives. I am grateful to an anonymous reviewer for bringing this to my attention.

${ }^{\mathrm{I}}$ am grateful to Julie Legate for providing these sentences.

An earlier version of this paper was presented at the $19^{\text {th }}$ annual meeting for Austronesian Formal Linguistics Association (AFLA-19), held at Academia Sinica, Taipei, 28 June 2012 and the $20^{\text {th }}$ Annual Meeting for International Association for Chinese Linguistics (IACL-20), held at Polytechnic University, Hong Kong, 29 August 2012. I am grateful to the audience there, in particular, Edith Aldridge, Paul Li, Lisa Travis, and Tong Wu for their helpful comments. I am grateful to three anonymous reviewers for their insightful comments. Thanks are also due to Chaokai Shi and Chunming Wu for reading an earlier draft and giving useful suggestions. I am indebted to my principal language consultants Mo'e Peongsi (Mo'o Peongsi), Mo'e Yakumangana (Mo'o Yakumangana), Sayung'e Yulunana (Sayungu Yulunana). I wish to thank my research assistants Chia-fen Wu and Maochang Ku for their typographic assistance. This study is funded by the National Science Council of Taiwan and the Institute of Linguistics of Academia Sinica. The usual disclaimer applies. 
Received: 28 June 2014 Accepted: 22 January 2015

Published online: 11 May 2015

References

Aldridge, Edith. 2004. Ergativity and word order in Austronesian languages. Ph.D. dissertation: Cornell University.

Aldridge, Edith. 2005. Phase theory account of absolutive extraction in Tagalog. In MIT working papers in linguistics 49:

Perspectives on phases, ed. Martha McGinnis and Norvin Richards, 1-27. Cambridge, MA: MIT Working Papers in Linguistics.

Aldridge, Edith. 2008a. Minimalist analysis of ergativity. Sophia Linguistica 55: 123-142.

Aldridge, Edith. 2008b. Phase-based account of extraction in Indonesian. Lingua 118(10): 1440-1469.

Alsina, Alex, and Sam A Mchombo. 1993. Object asymmetries and the Chichewa applicative construction. In Theoretical aspects of Bantu grammar, vol. 1, ed. Sam A Mchombo, 17-46. Stanford: CSLI Publications.

Baker, Mark. 1985. The mirror principle and morphosyntactic explanation. Linguistic Inquiry 16(3): 373-415.

Baker, Mark. 1988. Incorporation: a theory of grammatical function changing. Chicago: University of Chicago Press.

Bresnan, Joan, and Lioba Moshi. 1990. Object asymmetries in comparative Bantu syntax. Linguistic Inquiry 21(2): 147-185.

Büring, Daniel. 2004. Binding theory. Cambridge, MA: Cambridge University Press.

Chang, Melody Y-Y. 2004. Subjecthood in Tsou grammar. M.A. thesis: National Tsing Hua University.

Chang, Henry Y. 2009. Adverbial verbs and adverbial compounds in Tsou. Oceanic Linguistics 48(2): 339-376.

Chang, Henry Y. 2010. The high-low dichotomy and Tsou applicatives. In Paper presented at the 17th Annual Conference of the Austronesian Formal Linguistics Association (AFLA-17). New York: Stony Brook University.

Chang, Henry Y. 2011a. Transitivity, ergativity, and the status of $O$ in Tsou. In Language and cognition: Festschrift in honor of James H.-Y. Tai on his 70th birthday, ed. Jung-hsing Chang, 277-308. Taipei: The Crane Publishing Co.

Chang, Henry Y. 2011 b. Triadic encoding in Tsou. Language and Linguistics 12(4): 799-843.

Chang, Henry Y. 2011c. Tsou case markers revisited: visibility, proximity, and beyond. In Diversity of languages: papers in honor of Professor Feng-fu Tsao on the occasion of his retirement, ed. Raung-fu Chung, Wei-Tien Dylan Tsai, Ying Cheng, Su-ying Hsiao, and Hsiu-Hsueh Liu, 91-123. Taipei: The Crane Publishing Co.

Chang, Henry Y. and Marie M. Yeh. 2008. Deriving thematic mismatches in Formosan languages. Paper presented at CIL-18, Seoul University, Korea, July 21-26.

Chomsky, Noam. 1995. The minimalist program. Cambridge, MA: MIT Press.

Chomsky, Noam. 2000. Minimalist inquiries. In Step by step: Essays in minimalist syntax in honor of Howard Lasnik, ed. Roger Martin, David Michaels, and Juan Uriagereka, 89-155. Cambridge, MA: MIT Press.

Chomsky, Noam. 2001. Derivation by phase. In Ken Hale: A life in language, ed. Michael Kenstowicz, 1-52. Cambridge, MA: MIT Press.

Chomsky, Noam. 2008. On phases. In Foundational issues in linguistic theory: essays in honor of Jean-Roger Vergnaud, ed. Robert Freidin, Carlos P Otero, and Maria Luisa Zubizarreta, 134-166. Cambridge, MA: MIT Press.

Cinque, Guglielmo. 1999. Adverbs and Functional Heads. New York: Oxford University Press.

Cole, Peter, and Min-Jeong Son. 2004. The argument structure of verbs with the suffix -kan in Indonesian. Oceanic Linguistics 43(2): 339-364.

Dixon, Robert MW. 1994. Ergativity. New York: Cambridge University Press.

Donohue, Mark. 1996. Bajau: a symmetrical Austronesian language. Language 72(4): 782-793.

Georgala, Efthymia. 2012. Applicatives in their structural and thematic function: A minimalist account of multitransitivity. Ph.D. dissertation: Cornell University.

Harley, Heidi. 2002. Possession and the double object construction. Linguistic Variation Yearbook 2(1): 31-70.

Holmer, Arthur. 1999. Structural implications of the function of instrumental focus in Seediq. In Selected papers from the Eighth International Conference on Austronesian Linguistics, ed. Elizabeth Zeitoun and Paul Jen-kuei Li, $423-454$. Taipei: Academia Sinica.

Huang, Huei-ju, and Shuanfan Huang. 2007. Lexical perspectives on voice construction in Tsou. Oceanic Linguistics 46(2): 424-455.

Kuo, Xi-Liang 郭锡良. 1998. On the rise and development of Archaic Chinese yi 介词 “以” 的起源和发展. Study on Archaic Chinese 古汉语研究 38: 1-5.

Larson, Richard K. 1988. On the double object construction. Linguistic Inquiry 19(3): 335-391.

Larson, Richard K. 2010. On Pylkkänen's semantics for low applicatives. Linguistic Inquiry 41(4): 701-704.

Legate, Julie A. 2008. Morphological and abstract case. Linguistic Inquiry 39(1): 55-101.

Marantz, Alec. 1993. Implications and asymmetries in double object constructions. In Theoretical aspects of Bantu grammar, vol. 1, ed. Sam A Mchombo, 113-151. Stanford: CSLI Publications.

McGinnis, Martha. 2001. Variation in the phase structure of applicatives. Linguistic Variation Yearbook 1(1): 101-142.

McGinnis, Martha. 2008. Applicatives. Language and Linguistics Compass 2(6): 1225-1245.

Newman, John. 1996. Give: a cognitive linguistic study. Berlin and New York: Mouton de Gruyter.

Paul, Waltraud, and John Whitman. 2010. Applicative structure and Mandarin ditransitives. In Argument structure and syntactic relations: a cross-linguistic perspective, ed. Maia Duguine, Susana Huidobro, and Nerea Madariaga, 261-282. Amsterdam: John Benjamins.

Pearson, Matthew. 2005. The Malagasy subject/topic as an A'-element. Natural Language and Linguistic Theory 23(2): $381-457$.

Pylkkänen, Liina. 2002. Introducing arguments. MIT: Ph.D. dissertation.

Pylkkänen, Liina. 2008. Introducing arguments. Cambridge, MA: MIT Press.

Rackowski, Andrea. 2002. The structure of Tagalog: specificity, voice, and the distribution of arguments. MIT: Ph.D. dissertation.

Rackowski, Andrea, and Norvin Richards. 2005. Phase edge and extraction: a Tagalog case study. Linguistic Inquiry 36(4): 565-599.

Radford, Andrew. 2004. Minimalist syntax: exploring the structure of English. Cambridge University: Press.

Richards, Norvin. 2000. Another look at Tagalog subjects. In Formal issues in Austronesian linguistics, ed. Ileana Paul,

Vivianne Phillips, and Lisa Travis, 105-116. Dordrecht: Kluwer Academic Publishers.

Richards, Norvin. 2010. Uttering trees. Cambridge, MA: MIT Press.

Samkoe, Lori M. 1994. Mapping multiple applicatives. M.A. thesis: Simon Fraser University. 
Shi, Chaokai and Atul Manqogo. 2013. On Takibaka multiple applicative constructions. Paper presented at AFLA-20, University of Texas at Arlington, May 17-19.

Sigurðsson, Halldór A. 2004. Icelandic non-nominative subjects: facts and implications. In Non-nominative Subjects Vol. 2, ed. Peri Bhaskararao and Karumuri V Subbarao, 137-159. Amsterdam and Philadelphia: John Benjamins.

Tallerman, Maggie. 1998. Understanding syntax. London: Arnold.

Travis, Lisa D. 1984. Parameters and effects of word order variation. MIT: Ph.D. dissertation.

Tsai, Wei-Tien Dylan. 2012. High applicatives are not high enough: a cartographic solution. Paper presented at 14th China's International Conference on Contemporary Linguistics, Xi'an International Studies University, China, May 11-13.

Vikner, Sten. 2006. Object shift. In The Blackwell companion to syntax, ed. Martin Everaert and Henk van Riemsdijk, 392-436. Oxford: Blackwell Publishing Ltd.

Yeh, Marie M. 2003. A syntactic and semantic study of Saisiyat verbs. Ph.D. dissertation: National Taiwan Normal University.

Zeitoun, Elizabeth. 2005. Tsou. In The Austronesian languages of Asia and Madagascar, ed. Alexander Adelaar and Nikolaus P Himmelmann, 259-290. London and New York: Routledge.

\section{Submit your manuscript to a SpringerOpen ${ }^{\circ}$ journal and benefit from:}

- Convenient online submission

Rigorous peer review

- Immediate publication on acceptance

- Open access: articles freely available online

- High visibility within the field

- Retaining the copyright to your article 